\title{
Growing up and apart: Gender divergences in a Chicagoland elementary school
}

\author{
RiCHARD CAMERON \\ University of Illinois at Chicago
}

A B S T R A C T

A characteristic of children's social orders is gender segregation. When children can
choose, girls play more with girls and boys with boys. This begins around age three
and peaks in later childhood. If children separate into same-gender groups, their
interactions across the gender line will not be as frequent as those with members of
the same sex. Following on Bloomfield's assertion (1933:46) that "density of
communication" results in the "most important differences of speech" within a
community, I predict that differences will increasingly emerge between girls and boys.
I test this using two sociolinguistic variables, (dh) and (ing), in the English spoken by
children in an elementary school. The prediction is supported. Results contribute to
research into language socialization and the acquisition of gendered linguistic expression.

Since Fischer's (1958) work, we have known that children may display gender correlations or constraints on sociolinguistic variables similar to those of adults. Yet, what is less well understood is when, how, and why this happens. In other words, assuming that gender constraints on sociolinguistic variables are acquired, when, how, and why do these constraints emerge in the speech of girls and boys as they grow up?

The research reported here seeks to provide answers to these questions. To account for how age and gender interact in the acquisition of gender correlations in preadolescence, I combine findings from social psychology on the childhood practices of gender segregation with a basic principle of dialect divergence, Bloomfield's (1933:46) "density of communication." From these bases, I derive a prediction, initially foreshadowed in Cameron (2005a:54 n9). Next, I test the prediction in a study of two sociolinguistic variables, (dh) and (ing), in the English spoken by children from a public elementary school in Oak Park, Illinois, a town

I begin by thanking the children, the school administrators, teachers, and secretaries for their essential contributions to this project. Naomi Nagy and Julie Roberts provided very thoughtful comments on earlier versions of this work. Both have pushed me to rethink and rewrite, as have the numerous reviewers. I express my gratitude to all of these individuals. I thank the audiences at the Linguistic Society of America meeting in 2007, the American Dialect Society session at the 48th Annual Midwest Modern Language Convention in 2006, and New Ways of Analyzing Variation 34 conference in 2005 for their critical questions. My good friend, Elliot Judd, encouraged me to continue this research. Kirk Hazen responded generously to my emails about (ing). Para finalizar, les mando un abrazo a Diana González-Cameron, Miriam Meyerhoff, y Rena Torres Cacoullos por su consejos. 
within the Chicago metropolitan area known as Chicagoland. The findings support the prediction. The bases for the prediction, in turn, provide the framework for a social account of an emerging social pattern of language use in childhood.

THE EMERGENCE/ACQUISITION OF VARIATIONIST GENDER

CORRELATIONS, BLOOMFIELD'S PRINCIPLE, AND THE

GUIDING PREDICTION

After the first two or three years of life, children increasingly and actively socialize themselves and others through play, friendship, and the multiple language practices that play and friendship involve (Boyle, Marshall, \& Robeson, 2003; Eckert, 1996; Goodwin \& Kyratzis, 2007; Harkness \& Super, 1985; Kerswill, 1996; Kyratzis, 2004; Martin \& Ruble, 2004; Paugh, 2005; Thorne \& Luria, 1986; Whiting \& Edwards, 1988; Willett, 1995).

During the first two years of life, the very young are usually very involved in the socializing arms, laps, and speech of their families. With respect to gender expression, Eckert and McConnell-Ginet (2003:17) make a related point when they observe that a "newborn initially depends on others to do its gender." Doing gender for the very young may also be involved in the child-directed speech investigated by Ely, Gleason, and McCabe (1996) and Foulkes, Docherty, and Watt $(2005: 189,198,200)$. In their study, Foulkes et al. reported that mothers provided gender-differentiated input even before their children produced significant gender differences in their own speech. They did this by providing higher relative rates of standard variants in speech to young girls and, conversely, higher relative rates of nonstandard variants to young boys. In terms of speaker production, this particular correlation has been documented frequently in variationist studies of gender (Fischer, 1958; Labov, 1990; Meyerhoff, 2006:207). More broadly, Foulkes et al. (2005:199-200) also suggested, in line with Roberts (2002:342-343), that for the very young, "the choices parents make serve to introduce children to socially structured linguistic alternatives."

With respect to the children's own gendered output, Foulkes et al. (2005:300) reported that gender differences may emerge at about 3.6 ( 3 years, 6 months) years of age, a stage in development when other variable features of the local dialect are also being acquired (Díaz-Campos, 2004; Grinstead, 2004; Guy \& Boyd, 1990; Kerswill, 1996; Kovac \& Adamson, 1981; Roberts, 1997; Roberts \& Labov, 1995; Silva-Corvalán \& Sánchez-Walker, 2007; Youssef, 1991). As children continue to grow up, gender differences increasingly appear in their speech. Initially, these differences emerge unevenly with degrees of difference waxing and waning in a matter of months. The differences also occur with some variables but not others or occur in ways that may differ from older child and adult patterns.

Waxing and waning is seen clearly in Foulkes and Docherty's (2006:424) presentation of data on preaspiration of word-final /t/ in the English dialect of Newcastle. Focusing on children ranging in age from 2 to 4 years, the 2- and 3 -year-old boys and girls showed no significant gender difference, whereas those 
of 3.6 years of age did. The 4-year-old group continued this trend, but did not reach "significance at the 5\% level." Another relevant case is Smith, Durham, and Fortune's (2007) study of the "hoose variable" in Scottish children ranging in age from 2.10 to 3.6 years. Though the variable shows gender correlations among adults (p. 71), the children did not show a significant gender difference (p. 74) in their alternation between the diphthong and monophthong variants. If the adults show gender differences where these young children do not, it is reasonable to assume, via inductive inference, that the children will eventually acquire and reproduce these differences. An exception would be a change in progress in which gender correlations for a given variable are being lost (Cameron, 2005a:50).

Previous work by Roberts (1996) on preschool children in Philadelphia also demonstrated that young children's variable language behavior might not initially show the gender correlations of the adult community. For instance, for English (ing), Roberts (p. 162) found no significant differences between the genders. For $(-t, d)$ deletion (p. 116), contrary to expectation, the girls showed a greater probability of deleting than the boys. Prior to Roberts, Patterson (1992) also investigated the English variable (ing) using interview and task data from three groups of children ranging in age from 4 to 6 to 8 years. In brief summary, she found (p. vii) "no statistically significant differences between boys and girls, although 8-year-old boys used casual variants more than 8-year-old girls in every situation." This research suggests that gender correlations emerge as trends first and later acquire degrees of difference that reach statistical significance.

With respect to other social or stylistic meanings associated with sociolinguistic variables, young children and adults may also differ. In Ladegaard and Bleses' (2003:228) study of 4- to 6-year-old speakers of Danish, they suggested that children this young "are unaware of the social connotations" of sociolinguistic variables. Kerswill (1996:190) made a related point about the divergent behavior of a group of 4-year-old children when compared with their parents' /t/glottaling and /h/-deletion in English. If so, then "social connotations" are also acquired, some of which may also involve gender connotations (Edelsky, 1977; Johnson, 2006; Strand, 1999). These connotations may possibly be acquired during acts of stylistic variation (Eckert, 1996:188-189; Youssef, 1991:96), an aspect of variation documented in young children in both Spanish and English (D’Arcy, 2005; Diaz-Campos, 2005; Fischer, 1958; Labov, 1989; Reid, 1978; Romaine, 1984:95-104; Smith, Durham, \& Fortune, 2007). Nonetheless, the order in which style and gender correlations are learned is not fully clear. For instance, Patterson's (1992:127) findings indicated that children display certain stylistic uses of (ing) before significant gender correlations emerge.

Díaz-Campos (2005) investigated style and social class in Venezuelan preschool children in the age groups of 4 to 4.4 years and 4.5 to 5.9 years. He reported a style pattern (pp. 61-62) in the older children for retention of intervocalic (d) that parallels adult patterns, but not in the younger group. Díaz-Campos (p. 63) also found a clear quantitative class distinction, upper versus lower, overall among these children that likewise parallels adults. However, he did not separate the younger from the older children for the class variable. 
Other variationist research in French suggests that although the acquisition of stylistic variation begins early, style does not emerge robustly until children are between the ages of 6 and 12 years (Chevrot, Beaud, \& Varga, 2000:316). Kerswill and Williams (2000:103) provide a similar finding in their study of children participating in the development of a new English dialect in the town of Milton Keynes. Comparing children of 4, 8, and 12 years of age, they find that the 12-year-olds "style shift consistently," whereas the younger ones do not. From this, they derive the "tentative" generalization that (p. 105) "children slowly gain sociolinguistic maturity in a manner that involves a gradual increase in the number of styles that are perceived and treated in an adult way." Of related interest is that during this period of development, children are also increasingly developing a "theory of mind" (Abrams, Rutland, Pelletier, \& Ferrell, 2009:226). This entails the ability to take the perspective of others, perhaps a key aspect of audience-design style shifting (Bell, 1984).

The upshot of much of this research is the following. Young children are engaged in the simultaneous acquisition of multiple types of constraints on variation at the same time that they engage in variation as a form of social practice. Their social practices involving linguistic variation can and do differ from adults or older children. As advocated by Eckert (1997:157), we could investigate these practices not by reference to adult norms but from the perspective of the children as they engage strategically in the use of language. Some of these strategic uses may be unique to childhood owing to the social contexts and life events of childhood. Some may be necessarily developmental. In other words, for cognitive reasons, as children acquire adultlike constraints on sociolinguistic variables, they may pass through a sequence of stages such that a given stage requires having passed through a preceding one. Whatever the case, in the process of learning constraints on variation also found in adults, linguistic constraints appear to be acquired before social or stylistic constraints. Yet, the order in which social and stylistic constraints are acquired is not yet fully agreed upon. ${ }^{1}$ One of these social constraints or social practices involves gender expression.

Beyond their early years, as children move outside the family circle, they begin to do gender on their own in multiple ways (Eckert \& McConnell-Ginet, 2003:1532; Fausto-Sterling, 2000:243-255). Part of this doing of gender would also entail making choices about who to play with and talk to (Boyle, Marshall, \& Robeson, 2003) as they progressively "move from parent-oriented networks to peer-oriented networks" (Kerswill, 1996:196). Echoing the previous quote from Foulkes et al. (2005:199), these choices and the results of these choices, then, serve to introduce children to social contexts of their own making.

For instance, where children have the option of choosing their playmates and friends, girls tend to play more with girls and boys with boys. Indeed, one widely documented and pervasive characteristic of children's emergent social orders is relative gender segregation (Fabes, Martin, \& Hanish, 2004; Maccoby, 1998). This practice becomes noticeable around the age of 2 or 3 years, peaks in early adolescence or late-middle childhood, ${ }^{2}$ and decreases at some point during the teen years. In other words, as children move from preschool through 
elementary school, they increasingly segregate themselves along lines of gender for purposes of friendship or affiliation. Related patterns of increasing gender segregation in childhood in six different cultures led Whiting and Edwards (1988:81) to propose that this is "a cross-culturally universal and robust phenomenon." I use the term segregate here as it is commonly used in social psychological studies of childhood. To segregate is to create a separation between groups, intended or not, on the basis of some perceived difference or commonality. The separation need not be absolute for segregation to occur.

If children tend to separate into same-gender peer groups, their spoken interactions across the gender line would not be as frequent as their interactions with members of the same sex. If less frequent, in keeping with Bloomfield's assertion (1933:46) that "density of communication" results in the "most important differences of speech" within a community, one may predict that statistical differences would increasingly emerge between girls and boys. In more focused terms, the combination of two premises, increasing gender segregation in childhood and Bloomfield's principle of "density," yields the following implication. If the degree of separation, and thereby distance, between girls and boys increases during preadolescence, the rates/probabilities/index values of variants of sociolinguistic variables expressed by girls and by boys will also diverge as the children mature from the early to the later grades of elementary school. Notice that this is a quantitatively falsifiable prediction rooted in findings from social psychology and a basic principle of dialect formation. Therefore, if the prediction is supported, the premises that give rise to the prediction provide a basis for accounting for the findings.

I will add two refinements to this prediction. First, the sociolinguistic variables targeted by this prediction are those that actually show gender patterning within the larger community to which the children belong. Second, after reviewing a number of prior publications in Cameron (2005a:44-52), most notably Labov (2001), it became apparent that variationist gender patterning among children is influenced not solely by gender and age practices, but also by the type of sociolinguistic variable in question. By type, I specifically mean stable variables, showing no change in progress, versus variables defined by their stage within an ongoing change in progress. I restate this finding in the form of three falsifiable predictions, the first of which is investigated here.

1. If the sociolinguistic variable is stable, then increasing divergence between elementary school age girls and boys will occur.

2. If the variable is unstable, a change in progress in the mid-range, then increasing divergence between elementary school age girls and boys will also occur.

3. If the variable is unstable, a change in progress in the end stage of change, then no divergence and little to no difference between elementary school age girls and boys will occur.

Variables that were identified as new and incipient changes in progress provided conflicting results. Because of this, I did not feel that I could make a coherent 
prediction about this type of variable. With respect to end stage variables, it appears that over the course of change, either these variables lose a variant or variants from the original set or the rates of variation between variants are dramatically reduced and reorganized. Variants represent linguistic options for speakers. If speakers have no options or reduced options for a given variable, no gender correlation may be statistically constructed. Stable variables and unstable mid-range variables provide options to speakers in the age groups studied here. Thus, the prediction of increasing gender divergence applies to sociolinguistic variables that are stable or, if unstable, at the mid-range point in the temporal course of change.

Although published in 1933, Bloomfield's concept or principle of "density of communication" has been taken up repeatedly, if not always cited, in numerous studies of linguistic change or divergence, the standard/nonstandard continuum, dialect formation or loss, and linguistic repertoire. Consider Bailey, Wikle, Tillery, and Sand's (1993:383) discussion of "barriers that impede the diffusion of linguistic innovations." These may be formulated as barriers to density of communication. Similar points apply to Wolfram and SchillingEstes' (1995:701) discussion of the loss of "the longstanding isolation of Ocracoke Island." With this loss of isolation comes increasing density of communication with "transplanted mainlanders," which, in turn, contributes to the loss of the local dialect as well. In a related vein, Kerswill (1996:179) argued that "it is contacts between speakers that are necessarily the conduit for the spread of linguistic features." Kerswill's "contacts between speakers" may also be understood as involving density of communication. Bloomfield's notion of "density" is likewise echoed by Milroy's use of "density" (1987:49$50)$ in her insightful approach to social networks. Consider her point that (p. 61) "extreme density produces a homogeneity of norms and values." The implication would be that divergence from such norms and values may occur among individuals who do not participate with equal density in the same network. Bloomfield's arguments, though far less developed, are remarkably similar in implication. Weinreich's (1953:viii) discussion of convergence and divergence in contexts of language contact as well as Eckert and McConnellGinet's (1992:468) observation on the development of "linguistic repertoire through contact with language used by those they speak with regularly" also imply ideas akin to the principle of density. Related implications may be drawn from Hinskens, Kallen, and Taeldeman (2000) on dialect convergence and divergence, Tuten (2003) on the role of accommodation in koineization, and Miller (2005) on the accommodation of immigrants to Cairene Arabic in Egypt. ${ }^{3}$

Labov (2001:19-20, 24,228, 261) explicitly discusses and critically evaluates the principle as applied to regional and social diversity. Trudgill (2008:251-252), in turn, cites both Labov and Bloomfield in his discussion of dialect contact and mixing while also referring to one of Keller's (1994:96) maxims of accommodation: "Talk like the others talk." Keller (p. 96) revises this slightly as "talk like the people around you." One may talk like others "around you" when face-to-face interaction with these 
individuals is repeatedly facilitated and density of communication proceeds. In effect, then, Trudgill (p. 252) recasts Bloomfield's principle of density in Keller's terms as a type of accommodation or drive toward "behavioral coordination." Thus, Bloomfield is relevant yet. However, none of this research explicitly extends Bloomfield's principle to convergence and divergence among female and male speakers at different stages of life as previously found in Cameron (2005a).

In the research presented here, I test this derived prediction, using variationist methods, in the English spoken by children from one public elementary school in Oak Park, Illinois, a town within the Chicago metropolitan area. The children, mostly African and European American, come from two age groups: 7 to 8 and 10 to 11 years of age. Their families are principally employed as professional, managerial, technical, and sales workers, with some variation across ethnicity. Comparisons across the two ethnic groups permit tests of the prediction across ethnicity, dialect, and, to some extent, social class. By working with elementary school children of these ages, this work also extends the sequence of younger age groups found in Foulkes et al. (2005), Ladegaard and Bleses (2003), Patterson (1992), Roberts (1996), and Smith et al. (2007).

In keeping with the macrosociological scope and the specific aims of the prediction (Cameron, 2005a:29), I focus primarily on the gender patterning of two stable sociolinguistic variables in English: word initial and internal (dh) and word final (ing). However, I also include information on internal linguistic constraints on the two variables primarily as a means of identifying where disproportionate distributions in the data may occur. Such disproportionate distributions of data may be represented in raw numbers and percentages of the total number of tokens. Thus, I will rely on frequencies and rates, not probabilities. ${ }^{4}$ This is more important for the morphological variable of (ing), as the (dh) variable is subject to very few linguistic constraints. Both variables have been extensively studied in multiple communities where they often show class, ethnicity, gender, and style correlations (Dubois \& Horvath, 1998, 2000; Fischer, 1958; Hazen, 2008; Herndobler, 1993; Houston, 1985; Labov, 1966, 2001:78-113; Reid, 1978; Trudgill, 1974; Wald \& Shopen, 1981). Patterns of increasing divergence between girls and boys emerge for both (dh) and for (ing). Although the patterns support the prediction, subsequent analysis of patterns of "polarization" (Martin \& Fabes, 2001:434) within the divergences also puts us in the position to raise additional questions for future research and to indicate the limits of the explanatory scope of the hypothesis. These results contribute to research into the actions, intentional and unintentional, direct and indirect, by which children linguistically socialize themselves and acquire gender correlations.

In the remainder of the article, I first review research that documents gender segregation. In turn, I clarify what the hypothesis is focused on and what it is not. Next, I touch on issues of school demographics and research method before testing the hypothesis. I discuss each variable separately, providing a short review of prior research into each. 
DOES GENDER SEGREGATION OCCUR AND INCREASE

DURING CHILDHOOD?

In Cheshire's (1982:21-22) study of adolescents in Reading, England, she crafted the following relevant observation.

\begin{abstract}
"At the Shinfield playground 3 speakers were boys and 11 were girls. Although they knew each other (in fact, two were brother and sister), the boys did not normally mix with the girls, and they were never recorded together... This sex division did not happen by design, but perhaps reflects the tendencies of members of this age group to spend most of their time with friends of the same sex."
\end{abstract}

Cheshire's insight into "the tendencies of this age group" is of interest for many reasons. For one, I suspect that the girls did not normally mix with the boys either. Both groups are responsible for the "sex division," though the paths of the girls and boys probably did cross at times. Additionally, I would argue that these "tendencies" themselves have "design," structure, and possible consequence. The tendencies are known to fluctuate in correlation to age differences (Cameron, 2005a; Ellis, Rogoff, \& Cromer, 1981; Thorne, 1993). This correlation is one type of design or structure.

Though clearly present in adolescence, these tendencies begin much earlier. Martin and Fabes (2001:431) reported that girls as young as 2 years old demonstrate a statistical preference for same-gender playmates first, and boys begin to do so a year later. In early adolescence or middle childhood, the practice of gender segregation peaks and is followed by a relative lessening in the teenage years. Similar summary statements occur in many publications in the field of social psychology where childhood gender segregation and its consequences have been extensively documented and explored at least since the early 1930s beginning with the work of Criswell (1939:18), Moreno (1934), and Parten (1933-1934). For related statements and findings see Benenson, Apostoleris, and Parnass (1998:11); Boyatzis, Mallis, and Leo (1999:93); Erwin (1995:xii); Hartrup (1983:109); LaFreniere, Strayer, and Gauthier (1984: 1958); Larson and Richards (1991); Maccoby (1988: 755-756, 1998:27); Serbin, Moller, Gulko, Powlishta, and Colburne (1994:7); Shrum, Cheek, and Hunter (1988:232); Strough and Covatto (2002:349-350); and Thorne (1993:51-52).

Fabes, Martin, and Hanish (2004) and Maccoby (1998) provided useful overviews of research into childhood gender segregation. Aydt and Corsaro (2003); de Guzman, Carlo, Ontai, Koller, and Knight (2004); Harkness and Super (1985); and Whiting and Edwards (1988) provided discussions of crosscultural similarities and differences. Despite some cross-cultural differences and despite a diversity of childhoods across cultures, which ethnographers have identified (Gaskins, 2006; Lareau, 2003; Levine, 2007), increasing childhood gender segregation has been documented in all societies in which childhood gender segregation has been studied. Given this convergence of findings from multiple researchers across multiple societies, and given the previously cited 
claim of being “cross-culturally universal” (Whiting \& Edwards, 1988:81), one may strongly expect, via inductive reasoning, that increasing gender segregation also occurs among the children in this school in Oak Park.

By way of support, consider the following brief exchange that I had with two 10year-old girls of European American background from the Oak Park school. All children's names are pseudonyms.

Richard: Have you guys had parties yet, like boy-girl parties or just um ...

Rachel: Well um ...

Richard: No boy-girl parties yet?

Rachel: There has been. But it's not like, well ... I had 'em all the time when I was young.

Anna: Yea.

Rachel: But, now it's getting more and more ...

Anna: Just girl.

Rachel: Well, a lot of people have sleep-overs. And so they just have girls.

Note that Rachel indicates that in the past, boys and girls went to parties together but not now as Anna claims such socializing is "just girl." This is consistent with the presence of increasing gender segregation.

This segregation or separation is not absolute. Consider these overlapping responses from two 10-year-old African American girls, Delia and Beyonce. Beyonce's emphatic "no!" overlaps the beginning of Delia's utterance and is thereby interpretable as an answer to my question, not a disagreement with Delia.

Richard: Would you guys ever talk to the boys really?

Delia: No, not all the time.

Beyonce: No!

Delia's statement does not imply an absolute lack of spoken interaction between the boys and girls, as she adds "not all the time." Both Delia and Beyonce conceded that sometimes the boys would talk to the girls. Right after the preceding exchange, I asked the following:

Richard: Do the boys ever try to talk to you?

Beyonce: Yup.

Delia: $\mathrm{mmhhm}$

Richard: What happens?

Beyonce: We end up goin' with one of 'em. 
Delia: Or they flirt with us or something.

Elsewhere in the interview with Delia and Beyonce, I asked about who is friends with whom in the two adjoining classrooms that these two girls shared. Consider their response.

Richard: Well, um, who hangs out together in these two classes?

Delia: Well ... usually it's me and her,

Richard: uhhuh

Delia: an'... mm

Beyonce: I could say ...

Delia: It's this girl in my class name Sherya.

Richard: uhhuh

Delia: She hangs out with a girl from her class name Annabelle.

Richard: uhhuh

Delia: And it's this boy from our class ... name Lewan. And he hangs out wit' the boy from her class name Donny.

Beyonce: Donny.

Richard: uhhuh

Delia: ummm

Beyonce: And we, we hang out with the other people in G4L.

Delia: And um sometimes we just bring the whole class together and we just do stuff together.

Beyonce: Like all of our close friends are like mostly, ... Like a lot of the girls hang out together and if it's warm or something, we play uh jump rope, but if it's not so warm, we play uh-then G4L practices the dance.

Again, from their statements, we may infer that friendships play out strongly, if not exclusively, along lines of gender. Lewan hangs with Donny. These are two boys. In contrast, Delia hangs with Beyonce, Sherya, Annabelle, and "the other people in G4L." G4L was a singing group in the school also known as "Girls for Life." Similar statements are scattered throughout the interview data where children talk of friends or talk of who they talk to. When boys talked of friends, they referred to other boys. When girls spoke of friends, they referred to other girls.

Away from schools as observation sites, Ellis, Rogoff, and Cromer (1981) provided parallel findings. They repeatedly observed children playing at home and in their neighborhoods. The children ranged from 1 to 12 years of age. Gender segregation was apparent and showed an interaction with age segregation 
such that children in same-sex groups were more often found in same- or near-age groups and children in mixed-sex groups were more likely to be found in mixed-age groups (p. 404). Notably, as the ages of the children increased, the incidence of mixed-age and mixed-sex groups decreased. In turn, the incidence of same- or near-age (p. 404) and same-sex companions (p. 405) increased. The largest increase in gender-segregation appeared to be between the ages of 5-6 and 7-8 years. The interaction of age and gender segregation has also been noted by Thorne (1993:51) and served as a key organizing principle in Cameron (2005a).

Not all longitudinal studies, however, find increasing gender segregation within the time frame or social context targeted by the study. Blatchford, Baines, and Pellegrini (2003) investigated playground games in four British schools among 7- and 8-year-olds. Although gender segregation among the children was very high, they found that for this age group on the playground, "the degree of sex segregation remained constant over the year" (p. 500). This indicates that during childhood, the degree of gender segregation may plateau for periods of time before either increasing or decreasing again.

Researchers such as Boyatzis, Mallis, and Leon (1999); Goodwin (2001); Richer (1990); and Thorne (1993) also found that gender segregation in childhood is constrained to some extent by type of situation or activity. In other words, this practice is not uniform across all situations and activities and within some situations it may fluctuate. If the practice of childhood gender segregation is contextually constrained, one may expect that adults could intervene to counteract the prevalence of the segregation in selected settings.

Lockheed (1986) reported on one attempt to engineer an increase in crossgender interactions within a group of fourth- and fifth-grade elementary school classes. Though successful within the classroom, Lockheed (1986:627) provided anecdotal evidence that once detached from the classroom setting and expectations, "immediately, the students reorganized themselves into same-sex groups." Related to Lockheed's observation are my experiences in the two fifthgrade classrooms. Within the two second-grade classrooms where I observed and interviewed children, the children were assigned seats. In these classes, the teachers interspersed girls and boys in rows or clusters of seats. However, in the two fifth-grade classes, the children were given the option of selecting their seatmates and forming desk clusters of three or four. In both classes, boys selected to sit with boys and girls with girls.

WHAT THE HYPOTHESIS DOES NOT ADDRESS; WHAT THE HYPOTHESIS DOES ADDRESS

The documentation of increasing gender segregation has led researchers to ask why gender segregation occurs in childhood (Maccoby, 1988, 1998; Pellegrini, 2004) and what consequences may follow. Many researchers appear to assume that gender segregation promotes socialization into gendered identities, behaviors, and sexuality (Boyle, Marshall, \& Robeson, 2003; Leaper, 1994; Maltz \& 
Borker, 1982; Martin \& Fabes, 2001; Tannen, 1994; Thorne \& Luria, 1986). This line of research within sociolinguistics, often termed the dual culture hypothesis, is not without criticism and debate (Cameron, 2005a:28; Cameron, 2006; Thorne, 1993:89-109; Uchida, 1992:557). However, neither this research nor critiques of this research address the implications of increasing childhood gender segregation within the framework of sociolinguistic variation. For instance, the frequently cited work of Maltz and Borker (1982) was based on discourse strategies such as question asking, topic control and shifting, interruptions, or the interpretation of troubles sharing. More crucially, their work sought to explain why men and women might, sometimes, misunderstand one another. Tannen (1994:31) also wrote of "linguistic strategies" such as "indirectness, interruption, silence versus volubility, topic raising, and adversativeness or verbal conflict." In turn, Cameron (2006:75-92) based her balanced critique in terms borrowed from discourse analysis, the neglected issues of power and dominance, and the questionable use of the dual culture hypothesis to account for the supposed moments of miscommunication between women and men.

Yet, none of these cited researchers investigates sociolinguistic variables such as English (dh) or (ing) nor have they applied these ideas to issues of linguistic divergence and convergence as pursued here and in Cameron (2005a). As far as I can tell, no published variationist research into young children considers the implications of increasing childhood gender segregation either. Finally, in contrast to the dual culture hypothesis, I do not seek to explain why men and women may, sometimes, misunderstand one another nor do I make claims about the supposed existence of separate female and male cultures.

The primary purpose of this project is to test the prediction of divergence among girls and boys in different age groups given findings of increasing gender segregation in childhood. With Bloomfield in mind, my position is similar to Thorne and Luria (1986:179) when they claimed, "informal, gender segregated groups are powerful contexts for learning." I also attempt to address possible interactions of gender segregation with class and ethnicity. The need to consider gender as intersected by other social categories of experience is implicit in Thorne's (1993:108) admonition that researchers consider "which boys or girls, where, when, and under what circumstances." This recalls work by Eckert (1989:254), Nichols (1983:59), Ostermann (2003), and most recently Levey (2006:434), all of whom have proposed that we attend to the diversity within groups of females or within groups of males. The present work targets some of these previous gaps by intersecting two age groups with two ethnicities and dialects, as well as social class to some extent. Thus, comparisons will be made across and within the groups of girls and boys.

Although a longitudinal study of children would be the ideal method of testing the prediction, I organize the children according to their grade, and thereby age, within school. This results in a cross-sectional study similar to the arrangement of age groups in apparent time studies of language change or levels of proficiency in second-language acquisition research (Bardovi-Harlig, 2000; Boberg, 2004; Cardoso, 2007; Sankoff \& Blondeau, 2007). The prediction will 
be supported if statistical difference increases as the age of the children also increases. A pattern of convergence or a lack of difference across the groups would count as falsification of the hypothesis.

What does divergence look like? Consider the investigation of Wolf and Jiménez (1979) into a change in progress affecting the voicing of the prepalatal fricative ( $\check{z}$ ) in the Spanish of Buenos Aires. As part of their social analysis (p. 138), they intersected seven age groups with female and male speakers. The two youngest groups were 9- and 12-year-old girls and boys. Among the 9-year-

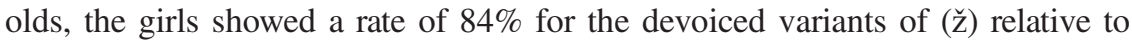
the boys' rate of $63 \%$. If we subtract the smaller $63 \%$ from the larger $84 \%$, we find that 21 percentage points separated the two groups. Among the 12-yearolds, the girls selected the devoiced variants $80 \%$ of the time, the boys $34 \%$. Subtract $34 \%$ from $80 \%$ and a difference of 46 points emerges. Thus, the degree of difference increased from 21 percentage points among the 9-year-olds to 46 percentage points among the 12-year-olds. This is what increasing divergence looks like. This supports the prediction.

Turning to English, in their study of the emerging variety of Milton Keynes English, Kerswill and Williams (2000:104) provided rate data for the [t] variant of the word-medial (t) glottaling variable for girls and boys at the ages of 4, 8, and 12 years. Among the 4-year-olds, we find a difference of 22.9 percentage points. Among the 8-year-olds, there is a decrease to 18 percentage points separating the girls and boys. However, among the 12-year-olds, again the degree of difference increases to 31.1 percentage points. Thus, as we go from 4to 8 - to 12 -year-olds, we find an overall increase of 22.9 to 18 to 31.1 . The dip 5 among the 8 -year-olds is not predicted, but the overall increase is. This is also what increasing divergence looks like.

What would outright contradiction of the hypothesis look like? Consider Romaine's (1984:100-102) discussion of the English variable (au) in the Edinburgh speech of boys and girls across three age groups of 6, 8, and 10 years. Using index values for the variable (p. 102), Romaine reported that the degree of difference between the girls and boys decreased from the youngest to the oldest groups. Among the 6-year-olds, the degree of difference was 43 index points; among the 8-year-olds, 25, and finally among the 10-year-olds, only 1 index point separated the girls and the boys. This is a pattern of increasing convergence. Thus, in the data from Romaine, there is reason to doubt the hypothesis as applied to all variables.

The hypothesis, where supported, provides a basis for an account. This is what theory is intended to do. In Hempel's (1966) philosophical treatment of scientific inquiry, he made the related assertion (p. 15) that "scientific hypotheses and theories are not derived from observed facts, but invented in order to account for them." If the data support the prediction, an account would then be found in the premises that give rise to the hypothesis. This does not mean that the account is right in some absolute sense, merely that it follows plausibly from the premises that gave rise to the hypothesis and prediction. I refer here to the common assumption in science that one cannot prove a theory. We can only falsify or 
support it. Moreover, as with any scientific account, only through replication of the study by different researchers can confidence in the account be increased. In turn, where the hypothesis is not supported, we are left with two interesting results. One, we know that the hypothesis is wrong for this particular data set, a useful finding. Second, we can then explore other reasons in a focused fashion, after the fact, that either we overlooked or did not think of. In this project, however, the patterns of increasing divergence support the hypothesis.

SOME NOTES ON FIELD METHODS AND SCHOOL

DEMOGRAPHICS

During the late fall and early spring of 2003 and 2004, I gained access to the Oak Park school as part of a larger project aimed at gathering sociolinguistic interview data in English across the Chicago metropolitan area. In early 2003, I had sought advice from the school principal on how I might do dialect research among the second and fifth graders of this kindergarten through fifth-grade elementary school. With his informal approval, I then sought approval from the local school board. The Oak Park School Board requested that I provide a written report on the English dialects spoken by the children and discuss any possible educational implications that these findings suggested. In that report, I summarized a number of dialect differences that I found between the speakers of the local varieties of African American Vernacular English and Inland North American English, the regional dialect that includes Chicago and Oak Park (Cameron, 2005b; Craig \& Washington, 2006; Gordon, 2001; Herndobler, 1993; Labov, Ash, \& Boberg, 2006:121; McCarthy, 2007).

With approval from the school board, I then contacted individual teachers in the targeted grades. Each second and fifth grade had three classrooms. In each case, one teacher declined to participate. This left me with access to two class groups per grade. During the initial appointment with an individual teacher, I arranged to observe and help in class for two to four mornings within a one-week period. During this period of observation, the children saw me and I saw them. I was also able to meet some of them, take notes on patterns of interaction, the schedule of classroom activities, and topics that I might later pursue when speaking with them. In the two second-grade classes, I specifically assisted the teachers by providing supplemental and individualized reading and mathematics activities designed by the teachers. Outside of the classroom, I was also able to observe playground play, either before school or during recess sessions. I also took notes on who played with whom and what the children seemed to be doing. Then, on the Friday morning of the week of classroom observation, I spoke to each class that I was targeting for about 10 minutes at the beginning of the school day. I did this to explain the project, the interview format, and then to distribute consent forms. I explained the project to both school personnel and the children as involving research into dialects of English in the Chicago area in which my major instrument of choice was the tape-recording of fun conversations. 
With help from the teachers, I arranged interviews with pairs of children once or twice a week for a number of weeks until I had interviewed all children who had consented. When pairing children for interviews, I sought the advice of teachers on the assumption that they would know much more about friendships among the children and about individual children than I did. I also suspected that teachers would know which children might have been in conflict to avoid pairing children currently at odds, an issue noted in Willet (1995:482). This turned out to be true. In addition, I asked the children whom they would prefer to be interviewed with. Where possible, I accommodated those requests.

Following on teachers' suggestions and my previous research experiences with children, the majority of the pairings for interviews were girls with girls and boys with boys. I did only one mixed interview with a second-grade boy and girl that I did not include in the final analysis. Pairs, at least for girls, have also been claimed by Willet (1995:482) to be a "basic unit" of interaction among the first-grade children in her school ethnography. Also, recall Labov's (1972:205-213) famous exposition on the interviewing success of Clarence Robins with the two 8-year-old boys, Leon and Greg, and the felicitous but crunchy role of potato chips. In fact, the pairing of girl with girl and boy with boy was intended to help the children feel more comfortable in the interview in keeping with Labov's notes (1972) on the utility of pairing children for interviews.

In the process, I interviewed 42 children, always in pairs, with 19 being in second and 23 in the fifth grade. I will report on 30 of these children though all 42 inform the demographic report on the school. In terms of ethnicity, 24 (57\%) of the original 42 were of European American background, 13 (31\%) were African American, 3 (7\%) self-identified as "mixed" (Puerto Rican and European, Mexican and African American, African American and European), and 1 child $(2 \%)$ claimed Chinese descent. The young girl of Chinese descent, however, had been adopted into a family of European American background as an infant, and, according to her mother, she had no regular access to a Chinese American community. I included her with children of European American descent owing to her adopted family background and apparent dialect features. Adopted children with ethnic or national origins that differ from those of their parents are not uncommon in this school. Overall, my initial sampling approximated the general ethnic representation of the school as depicted in Table 1.

After working through each recording of the interviews, I decided not to include 12 children in the analysis for various reasons. When interviewing young children in pairs, it is often the case that one child will dominate the conversation. Thus, a few children simply did not speak enough. In a few other cases, the children were so excited to be with me during their lunch break, that they spent most of the interview singing or laughing. Two children had braces or expanders that impeded their speaking. In one case, I had to cut short an interview as two second-grade boys began to throw food and managed to disconnect the microphones repeatedly. I also choose not to include two of the "mixed" children and one African American boy who, like the girl of Chinese descent, had also been adopted at an early age, though not an infant, into a family of European American descent. He 
TABLE 1. General demographics of a public elementary school in Oak Park, Illinois In the Illinois School Report Card (http://www.isbe.state.il.us/) for the year 2004, which covers the academic year of 2003-2004, we find the following information:

\begin{tabular}{lcccccc}
\hline \hline White & Black & Hispanic & Asian & Native American & Low Income $^{a}$ & Limited English Prof. $^{b}$ \\
\hline $67.0 \%$ & $28.9 \%$ & $2.2 \%$ & $1.9 \%$ & $0.0 \%$ & $-\%$ & $\%$ \\
\hline \hline
\end{tabular}

a"Low Income students come from families receiving public aid; live in institutions, for neglected or delinquent children; are supported in foster homes with public funds; or are eligible to receive free reduced-price lunches." In the report from 2003, low income was identified at 13.9\%. For some reason, in 2004, these figures are not provided.

"'Limited English Proficiency students are those students eligible for transitional bilingual programs." In the report from 2003, limited English proficiency was identified at 0.8\%. For some reason, in 2004, these figures are not provided. Quotes above come from the School Report Cards.

also claimed to have occasional contact with his African American siblings from the original family, though none with the birth mother. It was not clear to me if the dialect produced by this child was African American ${ }^{6}$ or that of the Inland North or both. The same was true of the two children who claimed mixed ethnicities. The term mixed was their term. They self-described themselves in this fashion and wanted me to use that term when writing about them. These exclusions resulted in 30 children with 13 in second and 17 in fifth grades. See Table 2.

I was able to interview the pairs of children for 45 to 55 minutes during their lunch break. I escorted the children to and from their classrooms and to and from the interview site within the school. During these escorts, I started conversations with the children prior to turning on the tape recorders when we arrived at the interview site. In this fashion, the first 5 minutes or so of all of the interviews were unrecorded. With some children, this initial unrecorded section was longer as we would stop to talk about artwork, writing samples, or athletic trophies on display in the hallway.

The interviews occurred in a room that was part of the main administrative suite for the school. I began each recording session by giving the children pizza and cans of Hawaiian Punch. The children uniformly liked this ("This is the best lunch in the year!" exclaimed Craig, a second-grade boy chewing loudly), but it did cause problems for the beginning of the recordings, which I will call the mouth-fullof-pizza-and-Hawaiian-Punch effect. As they were beginning to eat, I set up the microphones, continued the conversation begun before recording or asked some general demographic questions about their families.

Children liked to talk about pets, video games, playground games or sports, school projects, books they were reading in class or stories they already knew such as "Little Red Riding Hood" or the Harry Potter books, something that happened that was yucky or disgusting, scary movies and scary places at home, games or sports they played during the summer, Pokémon cards, visits to museums, dreams and déjà vu experiences, the layout of their homes, posters in 
TABLE 2. Number of children per grade included in the study

\begin{tabular}{lccr}
\hline \hline & African American & European/Latino/Chinese & Total \\
\hline $\begin{array}{l}\text { Fifth grade: Gender and ethnicity } \\
\text { (Ages: } 10-11 \text { years) }\end{array}$ & & & \\
Females & 4 & 6 & 10 \\
Males & 2 & 5 & 7 \\
Total & 6 & 11 & 17 \\
Second grade: Gender and ethnicity & & & \\
(Ages: 7-8 years) & & 4 & 7 \\
Females & 3 & 4 & 6 \\
Males & 2 & 8 & 13 \\
Total & 5 & & \\
\hline \hline
\end{tabular}

their rooms, Halloween costumes, ghosts, Christmas presents, coolest superheroes (Spider-Man or Superman?), popular musicians, and musical instruments. In some interviews, I spoke very little as the children themselves would fall into lengthy discussions among themselves about pet incidents or conflicts on the playgrounds or disagreements about which video games were for teenagers and which for younger children. In these cases, I kept quiet and asked questions only when the discussion seemed to be winding down. For the second graders, following on activities that I had observed in one class, I brought along a bucket of Lego toy building bricks and two coloring books on dinosaurs. After about 30 minutes, some second graders did not want to sit still and talk. We would take out the Lego bricks or the coloring books and play to keep the children occupied. I continued to record during this play period, though the children became very focused and quiet, occasionally animating their play with sound effects or humming. Thus, this short play period resulted in very little speech that was useful for analysis. ${ }^{7}$

As shown in Table 2, the groups of children are defined primarily on the basis of age/grade, ethnicity, and gender. Specifically, eight groups are represented: two gender by two ethnic groups per second and fifth grade. My goal in this research is to compare and contrast across and within these groups. Therefore, the primary unit of analysis is the group, not individuals within these groups. These comparisons result in a type of within-group analysis where the larger groups may be understood simply as girls and boys in this Oak Park school. These are then subdivided into smaller groups for analysis. This approach is motivated by the macrosociological nature of the hypothesis and the goal of considering gender as intersected by other social categories of experience, as noted previously (Cameron, 2005a:29). Given the number of groups involved, given the scope of access I was provided in the school, and given that my primary goal is to compare across and within these groups, early in the process it became apparent that a long-term ethnographic approach to the study of peer group social networks was not feasible. Thus, I did not principally rely on the participant-observer methods advocated and practiced expertly by Cheshire 
(1982) and Eckert (1996, 2000). The ethnographic approach has yielded fundamental insights that the survey method here practiced has not. For discussion of some methodological issues with the ethnographic approach in variationist studies, both strengths and potential limitations, see Dubois and Horvath (2000:289-291), Eckert (2000:70-78), and Labov (1990:208-210).

When doing sociolinguistic survey research of the type I pursued, a researcher is confronted with two key questions in school settings. First, beyond the issues of how to gain access and consent, during the school day, when can the researcher with recording equipment sit down with children to do a sociolinguistic interview? Second, where can this happen? Answers to these questions, in my experience, are best found in consultation with teachers and school administrators for two reasons. One, I did not want to interfere with their work. Two, I wanted to create a working relationship both with the children and with the school personnel in order to benefit from their knowledge. Cooperation with them is also necessary in order to successfully negotiate access and consent.

With respect to identifying social class backgrounds of the students, I relied on reports of the occupations of the mothers and/or fathers or other guardians of the children. I cite here only the occupations of adults with whom the child reportedly lived. I gathered these reports from the parents on the consent form, if they provided that information, or from the children during the interview. I was also able to speak on the phone to some parents who asked that I call them before doing any interviews. Teachers were also able to provide some clarifying information on parents' occupations. I provide this information as demographic portrait of the children in this school and to provide a basis for class comparisons if researchers into other school settings wish to contrast their findings with those reported here.

Using the nine major occupational groupings (MOG) or the Standard Occupational Classification major groups established by the United States Bureau of Labor Statistics as a guide, I organized the reported occupations of the children's parents or guardians into a modified and ranked list of eight occupational groups. ${ }^{8}$ See Table 3. My ranking of these occupations follows but does not always directly match that provided by the Bureau of Labor Statistics. I also consulted various occupational hierarchies discussed in Crompton (1993:50-60), Gilbert (1998), and Goldthorpe and Hope (1974).

Within this school, the children of African American and European American backgrounds show somewhat differing occupational profiles. Of the occupations reported for the parents of European American children, 98\% fall within the top four categories with professionals being the majority at 55\%. The largest group of occupations reported for parents of African American children also fall within the professionals at $24 \%$. Also, $57 \%$ of the reported occupations for this group are likewise found in the top four occupational categories. Yet, when we turn to the lower four occupational groups, clear differences emerge. Only $2 \%$ of the reported occupations for the European American children are from the bottom four occupation groups compared with $43 \%$ for the African American children. The three children who claimed mixed ethnicities reported parental occupations 
TABLE 3. Reported occupations

$\%=$ Rounded of total reported per group

$(n)=$ Raw number of reports

\begin{tabular}{lcccc}
\hline \hline & $\begin{array}{c}\text { European } \\
\text { et al. }\end{array}$ & $\begin{array}{c}\text { African } \\
\text { American }\end{array}$ & Mixed & All \\
\hline Professionals & $55 \%(23)$ & $24 \%(5)$ & $33 \%(1)$ & $44 \%(29)$ \\
Administrative and managerial workers & $24 \%(10)$ & $9 \%(2)$ & $33 \%(1)$ & $20 \%(13)$ \\
Technical & $7 \%(3)$ & $9 \%(2)$ & $33 \%(1)$ & $9 \%(6)$ \\
Sales & $12 \%(5)$ & $14 \%(3)$ & 0 & $12 \%(8)$ \\
Administrative support, clerical workers & $2 \%(1)$ & $14 \%(3)$ & 0 & $6 \%(4)$ \\
$\begin{array}{l}\text { Precision production, craft, and repair } \\
\quad \text { occupations }\end{array}$ & 0 & $5 \%(1)$ & 0 & $2 \%(1)$ \\
$\begin{array}{l}\text { Production, transportation, equipment } \\
\text { operators and laborers, maintenance }\end{array}$ & 0 & $14 \%(3)$ & 0 & $5 \%(3)$ \\
$\begin{array}{l}\text { Service } \\
\text { Total } n \text { of reported occupations }\end{array}$ & 0 & $9 \%(2)$ & 0 & $3 \%(2)$ \\
\hline \hline
\end{tabular}

within the top three occupational groupings. Within the group of African American children represented in this study, we may say that the group itself is more diverse relative to social class as indicated by parent occupation than is the group of children of European American descent. Because of this, a within-school classbased comparison in Oak Park becomes fundamentally a comparison across ethnic groups. For more on the interaction of class and ethnicity among schoolchildren in a U.S. setting, see Lewis (2003).

A RETURN TO THE PREDICTION AND THE QUESTION OF WHY (dh) AND (ing)

By way of reminder, the derived prediction is this:

If the degree of separation, and thereby distance, between girls and boys increases during pre-adolescence, the rates/probabilities/index values of variants of sociolinguistic variables expressed by girls and by boys will also diverge as the children mature from the early to the later grades of elementary school.

The prediction will be supported if statistical divergence increases as the age increases of the groups of girls and boys here studied. Statistical divergence will be identified in a fashion identical to that illustrated in the previous discussion of data from Wolf and Jiménez (1979) into the prepalatal fricative (ž) among 9- and 12-year-old speakers of Buenos Aires Spanish. In contrast, a pattern of convergence or a lack of changing difference among girls and boys across the age groups would count as falsification. Recall Romaine's (1984:102) treatment of the variable (au) in three age groups of English-speaking children from Edinburgh. 
Why have I chosen to use the variables of (dh) and (ing)? First, as noted in Labov (2001:74-120), these two variables are stable. Thus, they satisfy one of the requirements of the prediction. Second, both variables appear in the speech of all of the children here studied. Third, these two variables occur with a greater frequency in speech than other possible syntactic variables. However, the variable of (ing) occurs far less frequently than (dh). This frequency difference also provides for tests of the prediction in variables that differ in their characteristic frequency of occurrence in speech. Fourth, the relative infrequency of (ing) may be owed to its morphological status (Hazen, 2006; Labov, 2001:87), whereas (dh) is a phonological variable. Therefore, the two variables also represent two different levels of the grammar. Finally, as previously noted, research across multiple communities has often found class, ethnicity, and gender correlations for these variables in adults.

I pursue a similar procedure for both sociolinguistic variables. First, I provide a brief background review of research into the variable. Second, I review data on the internal linguistic constraints to see if significant differences obtain. The test of significance is the Pearson chi-square test. I also use the information on linguistic constraints to identify where disproportionate distribution of the data may have occurred. Third, I turn to a test of the prediction of increasing gender divergences as we go from the younger to the older children, first within all of the children combined, then within each ethnic group.

TESTING THE PREDICTION: THE CASE OF (dh)

The variable of (dh) is one sociolinguistic variable that has actually been studied in Chicago, a much understudied urban dialect (Cameron, 2005b). Herndobler (1993) provided data on both (dh) and the related (th) variable in a south side neighborhood of Chicago. Aside from finding robust gender correlations, she argued that the substitution of stops for fricatives (p. 140) "is a well-known foreign language interference phenomenon ... [whose] presence in this community can be assumed to originate with the community's immigrant history." Eckert and McConnell-Ginet (2003:297) referred to unpublished research that provided related findings on Chicago (dh). Yet, Dubois and Horvath (1998:247), writing of both (dh) and (th), asserted that "for almost as long as the English language has had this pair of sounds, there have been variant pronunciations." Labov (2001:90-92) added historical perspective on this as well. Herndobler (1993:139) also quoted one member of the community indicating that the $[\mathrm{d}]$ variant of $(\mathrm{dh})$ is subject to overt commentary. This is a characteristic of a stereotype variable, at least for adults in the community, as defined by Labov (1994:78). Labov (1966, 2001) has investigated (dh) in both New York and Philadelphia. In both cases, (dh) showed gradient class and style correlations with evidence of gender differentiation as well. Finally, Dubois and Horvath (1998, 2000) investigated both (dh) and (th) across age, gender, and network type in Cajun communities in Louisiana. Correlations with gender 
clearly emerge but also display striking interactions with age and network. Yet, with the exception of the youngest male and female speakers in the closed network groups, all other pairings of male and female speakers find males favoring, relative to the females, the dental stop variant. This particular finding, the male favoring of the dental stop and the relative female favoring of the fricative, is a majority finding across these studies. However, in this particular community, one undergoing language shift from French to English, Dubois and Horvath (2000:296) also suggested that the community is undergoing a change involving a reassertion of local Cajun variants in which young men are leading. Thus, in the English of the Cajun community in Louisiana, (dh) may not be a stable variable.

In most cases, research into (dh) has focused on word-initial position (Labov, 2001:78), though the variable may be extended to word-final and word-internal positions (Wolfram \& Schilling-Estes, 2006:363). By word-internal, I specifically mean intervocalic or between a vowel and sonorant as in such words as brother or Mother. I included this context because I heard children producing the stop variant in these contexts. This is the only internal linguistic constraint studied here. These different positions also occur with slightly different sets of variants. I opted to focus strictly on the set of shared variants across these two contexts. Among these children, the set of variants that I have identified includes the voiced interdental fricative [ð], a voiced stop [d], and a null or deleted variant. I opted not to include the deleted variant because this occurred only initially, never internally. In a pilot study, I also found the deleted form to occur only in one word, the third-person plural object pronoun them. This differs slightly from Labov's (2001:78) set of variants for (dh), which included "dh-0 fricative, dh-1 affricate or absences, dh-2 stop." Contexts in which the preceding word ended with a clear apical stop, per Labov's (2001: 78) observation on neutralization, were also excluded. For each child, I coded the first 50 tokens of (dh). This usually meant that coding began anywhere from 5 to 10 minutes into the interview conversation because all of the interviews began while I escorted the children to the interview site. Also, at the beginning of the interviews, children ate pizza and slurped Hawaiian Punch.

Turning to Table 4, we begin by looking at the linguistic constraints of wordinternal versus word-initial contexts for all of the children combined. Notice two things. First, internal position highly favors the fricative variant relative to wordinitial position. This is highly significant. I use the conventional critical value of .05 as the level of significance required for chi-square values. I will report the various levels at which a chi-square value is significant only through .001 . Second, $94 \%$ of all tokens occur in the word-initial position. Therefore, if a given group happens to provide a distribution of tokens that differs dramatically from this pattern, we may need to redo the analysis in keeping with those linguistic constraints that are shared across the groups. However, turning to Table 5, for both ethnic groups, a similar ranking of internal constraints and a similar distribution of tokens emerge. Again, the internal constraint highly favors the fricative variant. Also, for the African American children, 96\% of the tokens occur in the word-initial context. For the children of European American 
TABLE 4. Overall for (dh) by word position-internal and initial—arranged most to least Chi-squared (for internal vs. initial) $=42.519$ percentage for $[ð]$

Significant at .001

\begin{tabular}{lcrrcc}
\hline \hline & {$[\varnothing]$} & {$[\mathrm{d}]$} & Total & $\begin{array}{c}\text { Rounded \% of } \\
\text { Total Tokens }\end{array}$ \\
\hline Internal & $n$ & 81 & 3 & 84 & $6 \%$ \\
Initial & $\%$ & 96 & 4 & & $94 \%$ \\
& $n$ & 865 & 551 & 1,416 & \\
Total & $\%$ & 61 & 39 & & \\
& $n$ & 946 & 554 & 1500 & \\
& $\%$ & 63 & 37 & & \\
\hline \hline
\end{tabular}

TABLE 5. Word position for (dh) by African American/European American: Arranged most to least percentage for [ð]

Chi-squared (for internal vs. initial) for African Americans = 17.35; for European

Americans $=22.78$

Significant at .001

African American vs. European American overall: chi-squared =91.598; significant at .001

\begin{tabular}{|c|c|c|c|c|c|c|c|}
\hline & & \multicolumn{3}{|c|}{ African American } & \multicolumn{3}{|c|}{ European American } \\
\hline & & [ð] & [d] & Total & $\overline{[ð]}$ & [d] & Total \\
\hline \multirow[t]{2}{*}{ Internal } & $n$ & 20 & 2 & 22 & 61 & 1 & 62 \\
\hline & $\%$ & 91 & 9 & & 98 & 2 & \\
\hline \multirow[t]{2}{*}{ Initial } & $n$ & 241 & 287 & 528 & 624 & 264 & 888 \\
\hline & $\%$ & 46 & 54 & & 70 & 30 & \\
\hline \multirow{2}{*}{ Total } & $n$ & 261 & 289 & 550 & 685 & 265 & 950 \\
\hline & $\%$ & 47 & 53 & & 72 & 28 & \\
\hline
\end{tabular}

descent, a comparable $93 \%$ of all tokens occur in word-initial position. I found similar distributions for all groups studied in both second and fifth grade. Despite these shared patterns of constraint ranking and token distribution, it is also clear that in quantitative terms, these children belong to different dialects. Where the African American children show rates of $47 \%$ for the fricative variant [ð], the European American children show a rate of $72 \%$. This highly significant difference justifies identifying them as members of different social dialect groups within the school.

Next, we move to a test of the prediction. See Table 6. I begin by comparing girls and boys in fifth and second grade overall. The prediction of increasing statistical divergence will be supported if the size of the differences between the rates of the [ð] variant for the girls and boys increases as one moves from second to fifth grade. As noted before, I derive the size of differences between a group of girls and boys within any given grade by subtracting the smaller rate from the larger rate for the fricative variant. 
TABLE 6. Fifth and second grades by boys and girls for (dh)

Point differences (for ð variant): for fifth grade: 27; for second grade: 6

Chi-square for girls vs. boys: for fifth grade: 64.94, significant at .001; for second grade: 2.24 , not significant at 05

\begin{tabular}{|c|c|c|c|c|c|c|c|}
\hline & & \multicolumn{3}{|c|}{ Fifth Grade } & \multicolumn{3}{|c|}{ Second Grade } \\
\hline & & д & d & Total & ə & d & Total \\
\hline \multirow[t]{2}{*}{ Girls } & $n$ & 370 & 130 & 500 & 231 & 119 & 350 \\
\hline & $\%$ & 74 & 26 & & 66 & 34 & \\
\hline \multirow[t]{2}{*}{ Boys } & $n$ & 164 & 186 & 350 & 181 & 119 & 300 \\
\hline & $\%$ & 47 & 53 & & 60 & 40 & \\
\hline \multirow[t]{2}{*}{ Total } & $n$ & 534 & 316 & 850 & 412 & 238 & 650 \\
\hline & $\%$ & 63 & 37 & & 63 & 37 & \\
\hline
\end{tabular}

In the fifth grade, using the rounded percentage points for the fricative variant, the point difference between the girls and boys is 27 . Also, the girls and boys reach a significant degree of difference. In the second grade, the point difference is 6 . Also, with a chi-square value of 2.24 , the girls and boys are not significantly different from one another. This increase of 6 to 27 supports the prediction.

Turning to Table 7, the same pattern is repeated within the set of African American and European American children. Among the African American children, girls and boys differ by 6 points in second grade and 30 points in fifth grade. Among the European American children, girls and boys differ by 10 points in second grade and, again, by 30 points in fifth grade. In both groups, the girls and boys are not significantly different in second grade, yet reach considerable levels of significant difference in fifth grade. In both groups, there is an increase in the point spread, which indicates increasing gender divergence, as we move from second to fifth grade. Thus, the prediction is again supported. Also notice that, despite the lack of significant difference among the girls and boys in second grade, a trend emerges similar to the one noted by Patterson (1992:vii) in her study of (ing). Recall that she investigated children ranging in age from 4 to 6 to 8 years. She found (p. vii) "no statistically significant differences between boys and girls, although 8-year-old boys used casual variants more than 8-year-old girls in every situation." This is also the case in the second-grade groups here for the [d] variant. In each group, the boys used relatively more of the [d] variant than the girls did and, conversely, the girls produced relatively more of the [ð] variant. Thus, in these age groups, gender differences appear initially as a trend.

\section{TESTING THE PREDICTION：THE CASE OF (ing)}

Unlike (dh), I have not identified any previous community-based sociolinguistic study of the (ing) variable in the Chicagoland area. However, given that numerous studies elsewhere have found gender correlations for this variable, I will assume, inductively, that similar findings would emerge in Chicago. Like 
TABLE 7. Fifth and second grades by boys and girls by ethnicity for (dh)

Point differences (for [ð] variant): for African Americans: fifth grade: 30, second grade: 10; for European Americans: fifth grade: 30, second grade: 6

Chi-square for girls vs. boys: for African Americans: fifth grade: 24.086 - significant at .001, second grade: 2.403 — not significant; for European Americans: fifth grade: 62.327 significant at .001, second grade: 2.486 - not significant

\begin{tabular}{|c|c|c|c|c|c|c|c|}
\hline & & \multicolumn{3}{|c|}{ African American } & \multicolumn{3}{|c|}{ European American } \\
\hline & & $\overline{[ð]}$ & [d] & $\overline{\text { Total }}$ & $\overline{[ð]}$ & [d] & Total \\
\hline \multicolumn{8}{|c|}{ Fifth grade } \\
\hline \multirow[t]{2}{*}{ Girls } & $n$ & 114 & 86 & 200 & 256 & 44 & 300 \\
\hline & $\%$ & 57 & 43 & & 85 & 15 & \\
\hline \multirow[t]{2}{*}{ Boys } & $n$ & 27 & 73 & 100 & 137 & 113 & 250 \\
\hline & $\%$ & 27 & 73 & & 55 & 45 & \\
\hline \multicolumn{8}{|c|}{ Second grade } \\
\hline \multirow[t]{2}{*}{ Girls } & $n$ & 78 & 72 & 150 & 153 & 47 & 200 \\
\hline & $\%$ & 52 & 48 & & 76 & 24 & \\
\hline \multirow[t]{2}{*}{ Boys } & $n$ & 42 & 58 & 100 & 139 & 61 & 200 \\
\hline & $\%$ & 42 & 58 & & 70 & 30 & \\
\hline
\end{tabular}

(dh), the variable (ing) has two variants: an alveolar and a velar nasal. CampbellKibler (2006:8-9, 2007:55) also identified this variable as a stereotype subject to overt commentary. It appears that (ing) has been a variable in English for a long time with the alternate variants being historically associated with different morphological origins. The alveolar variant is historically derived from the Old English present participle. Current internal constraints on (ing) reflect this in that nominal forms favor the velar variant and verbal forms favor the alveolar variant. Therefore, contrary to (dh), the variable (ing) is known to be constrained by a number of grammatical factors (Hazen, 2008:126; Houston, 1985, 1991; Labov, 2001:88). I will also investigate grammatical conditioning on this variable between both ethnic groups primarily to identify possible issues of disproportionate distribution in the data.

The variable (ing) occurs only in word-final position in multisyllabic words. I excluded cases of the Periphrastic Future of 'going to + Verb' because these tokens showed no variation. In all instances, 'going to' in these contexts was pronounced as 'gonna.' From the lexical set of 'anything,' 'everything,' 'something,' and 'nothing' I also excluded 'anything' and 'everything' as they were invariant in this data. Proper names, like "Julius Erving," were also excluded as they were uniformly velar. As noted, (ing) occurs less frequently than (dh) perhaps owing to its morphological status. Because of this, I was unable to gather 50 tokens per individual speaker. Instead, I reviewed the entire tape recording of each of the interviews and coded as many tokens of (ing) per child as I could find. In total, I gathered 1,018 tokens.

With respect to the internal grammatical constraints, I rely on Houston and Hazen as primary guides. Houston (1985:104) provided a variable rule analysis 
of the velar variant of (ing) for 19 grammatical constraints ranging from the set of \{no/some/any/everything $\}$ to prepositions. In subsequent analysis, she (p. 109) combined constraints with similar values and reduced the original 19 to 6 . Within either analysis, a scalar constraint ranking emerged such that nominals favor the velar variant relative to verbal forms. Hazen (2008:126) created a set of five grammatical constraints. These include progressives, adjectives, nouns, and then gerunds and gerund-participles, a distinction specifically derived from Huddleston (2002:126). Gerund participles occur within the verb phrase as the object of a preposition. Gerunds occur elsewhere.

I synthesized Hazen and Houston's constraints to create a set of seven grammatical constraints. In alphabetical order, they include adjectives, gerunds, gerund-participles, progressives and quasi-progressives, the set of \{nothing/ something \}, nouns where the form is not clearly associated with a verbal form or where the form is monomorphemic as in morning or evening, and prepositions. However, as I worked through the data, I noticed the special discourse character of the phrase "or something," a grammatical constraint not found in either Houston or Hazen. Given the tendency of discourse markers to undergo reduction, I opted to distinguish the phrase "or something" from the use of something as in the set of \{nothing/something\}. Thus, I will analyze eight grammatical constraints.

Overstreet (1999:3) has written of "or something" as a "general extender" or hedge. In all cases of "or something," this disjunctive phrase is immediately preceded by a discourse entity, attribute, or action. The preceding entity, attribute, or action implicates a set of which it is currently the salient member. The phrase "or something" then adds an open, or unspecified, variable that is specifiable within the criteria of the set implicated by the preceding entity, attribute, or action. The lack of precisely specified content in the variable implicates a fuzzy approximation to the value of the entity, attribute, or act that forms the first part of the disjunct. For example, consider this previously noted quote from Beyonce.

Beyonce: Like a lot of the girls hang out together and if it's warm or something, we play uh jump rope,

When she says, "if it's warm," she introduces the attribute "warm." This implicates a set of related though unsaid terms. The subsequent "or something" introduces a set-related unspecified variable that may be paraphrased as "or something like warm."

In the next example, Rebecca's "or something" implicates a similar intention, relative to the preceding "3 bucks." This entity, "3 bucks" implicates the set of how much you might pay for huge pieces of pizza and a soft drink. The addition of "or something" further implies that "3 bucks" is approximate. Overstreet (1999:105, 115) identified this as hedging or approximating.

Rebecca: Like, Nick's, you can get better deals cause you can get huge pieces and a pop for like 3 bucks or something, I don't know. 
TABLE 8. Overall for (ing) by grammatical constraint: Arranged most to least percentage for $[\mathrm{\eta}]$

Chi-square $=72.5$

$d f=7$

Significant at .001

\begin{tabular}{|c|c|c|c|c|c|}
\hline & & [y] & {$[\mathrm{n}]$} & Total & $\begin{array}{l}\text { Rounded } \% \text { of } \\
\text { Total Tokens }{ }^{a}\end{array}$ \\
\hline Preposition & $\begin{array}{l}n \\
\%\end{array}$ & $\begin{array}{c}5 \\
100.0\end{array}$ & $\begin{array}{l}0 \\
0.0\end{array}$ & 5 & $1 \%$ \\
\hline Noun & $\begin{array}{l}n \\
\%\end{array}$ & $\begin{array}{l}28 \\
90\end{array}$ & $\begin{array}{r}3 \\
10\end{array}$ & 31 & $3 \%$ \\
\hline Adjective & $\begin{array}{l}n \\
\%\end{array}$ & $\begin{array}{l}84 \\
87\end{array}$ & $\begin{array}{l}13 \\
13\end{array}$ & 97 & $10 \%$ \\
\hline Gerund & $\begin{array}{l}n \\
\%\end{array}$ & $\begin{array}{l}68 \\
85\end{array}$ & $\begin{array}{l}12 \\
15\end{array}$ & 80 & $8 \%$ \\
\hline Gerund participle & $\begin{array}{l}n \\
\%\end{array}$ & $\begin{array}{l}57 \\
71\end{array}$ & $\begin{array}{l}23 \\
29\end{array}$ & 80 & $8 \%$ \\
\hline Or something & $\begin{array}{l}n \\
\%\end{array}$ & $\begin{array}{l}43 \\
65\end{array}$ & $\begin{array}{l}23 \\
35\end{array}$ & 66 & $7 \%$ \\
\hline Nothing/something & $\begin{array}{l}n \\
\%\end{array}$ & $\begin{array}{l}28 \\
61\end{array}$ & $\begin{array}{l}18 \\
39\end{array}$ & 46 & $5 \%$ \\
\hline Progressives & $\begin{array}{l}n \\
\%\end{array}$ & $\begin{array}{r}337 \\
55\end{array}$ & $\begin{array}{r}276 \\
45\end{array}$ & 613 & $60 \%$ \\
\hline Total & $\begin{array}{l}n \\
\%\end{array}$ & $\begin{array}{r}650 \\
64\end{array}$ & $\begin{array}{r}368 \\
36\end{array}$ & 1,018 & \\
\hline
\end{tabular}

${ }^{a}$ Due to rounding, percentages may add up to more than $100 \%$.

Turning first to Table 8, I provide an initial overview of the rates of the two variants, the velar [n] and the alveolar [n] in the speech of the 30 children combined. As reported in Hazen (2008:126) and Houston (1985:109), the nouns show a higher favoring of the velar variant relative to the progressives. Gerunds and adjectives, as in Hazen, are also quite similar in rates. Compared with Houston's findings, however, differences occur with respect to the ranking of prepositions, and the category of nothing/something. Houston included anything and everything in this set. I excluded them as invariantly velar. Notice that the category that provides the majority of tokens is the progressive. Overall, progressives constitute $60 \%$ of the tokens. This particular pattern of token distribution, with slight differences in actual percentage, occurs in all groups. Also note the relatively small numbers of prepositions and nouns.

Similar rankings, per nouns, gerunds, and adjectives relative to progressives, emerge if one separates the African American and European American children into two groups. See Table 9. However, the constraints of "or something" and nothing/something are inverted. Among the African American children, "or something" overall has the highest rate of the alveolar variant. Among the European American children, the category of nothing/something has the highest alveolar rate. But, in both groups, again the progressives constitute the majority, 
TABLE 9. Grammatical constraints for (ing) by African American/European American: Arranged most to least percentage for $[\mathrm{g}]$

For African Americans, chi-square $=44.7$, significant at $.001, d f=6$

For European Americans, chi-square $=33.5$, significant at $.001, d f=7$

African American vs. European American overall: chi-square $=96.582$, significant at .001

\begin{tabular}{|c|c|c|c|c|c|c|c|c|c|}
\hline & & \multicolumn{3}{|c|}{ African American } & & \multicolumn{4}{|c|}{ European American } \\
\hline & & {$[\mathrm{y}]$} & {$[\mathrm{n}]$} & Total & & & {$[\mathrm{y}]$} & {$[\mathrm{n}]$} & Total \\
\hline \multirow{2}{*}{ Noun } & $n$ & 13 & 2 & 15 & Preposition & $n$ & 5 & 0 & 5 \\
\hline & $\%$ & 86.7 & 13.3 & & & $\%$ & 100.0 & 0.0 & \\
\hline \multirow[t]{2}{*}{ Gerund } & $n$ & 19 & 7 & 26 & Noun & $n$ & 15 & 1 & 16 \\
\hline & $\%$ & 73 & 27 & & & $\%$ & 94 & 6 & \\
\hline \multirow{2}{*}{ Adjective } & $n$ & 20 & 8 & 28 & Adjective & $n$ & 64 & 5 & 69 \\
\hline & $\%$ & 71 & 29 & & & $\%$ & 93 & 7 & \\
\hline \multirow[t]{2}{*}{ Gerund participle } & $n$ & 14 & 8 & 22 & Gerund & $n$ & 49 & 5 & 54 \\
\hline & $\%$ & 64 & 36 & & & $\%$ & 91 & 9 & \\
\hline \multirow{2}{*}{ Nothing/something } & $n$ & 9 & 7 & 16 & Or something & $n$ & 37 & 10 & 47 \\
\hline & $\%$ & 56 & 44 & & & $\%$ & 79 & 21 & \\
\hline \multirow[t]{2}{*}{ Progressives } & $n$ & 81 & 160 & 241 & Gerund participle & $n$ & 43 & 15 & 58 \\
\hline & $\%$ & 34 & 66 & & & $\%$ & 74 & 26 & \\
\hline \multirow[t]{2}{*}{ Or something } & $n$ & 6 & 13 & 19 & Progressives & $n$ & 256 & 116 & 372 \\
\hline & $\%$ & 32 & 68 & & & $\%$ & 69 & 31 & \\
\hline \multirow[t]{2}{*}{ Preposition } & $n$ & 0 & 0 & 0 & Nothing/something & $n$ & 19 & 11 & 30 \\
\hline & $\%$ & 0 & 0 & & & $\%$ & 63 & 37 & \\
\hline \multirow[t]{2}{*}{ Total } & $n$ & 162 & 205 & 367 & Total & $n$ & 488 & 163 & 651 \\
\hline & $\%$ & 44 & 56 & & & $\%$ & 75 & 25 & \\
\hline
\end{tabular}

and progressives, relative to nouns, favor the alveolar variant. Among the African American children, progressives provide $66 \%$ of the tokens. For the European American children, progressives provide $57 \%$. One may suspect that this difference contributes somewhat to the clear overall quantitative difference between the two ethnic groups with respect to their rates of variation. Observe that, as with (dh), the two groups are significantly different at the .001 level. However, focusing on the just the progressives, the majority category, one can still see clear quantitative differences. Among the African American children, a velar variant in a progressive occurs $34 \%$ of the time. Among the children of European American descent, the velar variant occurs at a rate of $69 \%$.

Also notice that there happen to be no prepositions represented in the African American database. Turning to Table 10, I further break down the token distribution according to gender, and ethnicity with the two grades initially combined. Note again that the progressives constitute the majority in all cases, but now we see that the African American boys happen not to provide either noun or preposition tokens. In Table 11, we find further evidence of three grammatical constraints that are not represented in all groups. Specifically, these are the nouns, prepositions, and "or something." All three are missing from the boys of European American descent in second grade. Also notice that the boys of European American descent in fifth grade appear not to have the majority of 
TABLE 10. Distribution of tokens of African American and European American (ing) per grammatical constraint by girls vs. boys: Most to least ${ }^{a}$

\begin{tabular}{|c|c|c|c|c|c|}
\hline & \multicolumn{2}{|c|}{ African American } & & \multicolumn{2}{|c|}{ European American } \\
\hline & $n$ & $\%$ of Total & & $n$ & $\%$ of Total \\
\hline \multicolumn{6}{|c|}{ Girls (fifth and second grades combined) } \\
\hline Progressive & 176 & $66 \%$ & Progressive & 228 & $60 \%$ \\
\hline Gerund & 19 & $7 \%$ & Gerund participle & 39 & $10 \%$ \\
\hline Adjective & 18 & $7 \%$ & Adjective & 31 & $8 \%$ \\
\hline Gerund participle & 16 & $6 \%$ & Or something & 30 & $8 \%$ \\
\hline Noun & 15 & $6 \%$ & Gerund & 22 & $6 \%$ \\
\hline Or something & 14 & $5 \%$ & Nothing/something & 19 & $5 \%$ \\
\hline Nothing/something & 10 & $4 \%$ & Noun & 9 & $2 \%$ \\
\hline Preposition & 0 & & Preposition & 4 & $1 \%$ \\
\hline Total & 268 & & Total & 382 & \\
\hline \multicolumn{6}{|c|}{ Boys (fifth and second grades combined) } \\
\hline Progressive & 65 & $66 \%$ & Progressive & 144 & $54 \%$ \\
\hline Adjective & 10 & $10 \%$ & Adjective & 38 & $14 \%$ \\
\hline Gerund & 7 & $7 \%$ & Gerund & 32 & $12 \%$ \\
\hline Gerund participle & 6 & $6 \%$ & Gerund participle & 19 & $7 \%$ \\
\hline Nothing/something & 6 & $6 \%$ & Or something & 17 & $6 \%$ \\
\hline Or something & 5 & $5 \%$ & Nothing/something & 11 & $4 \%$ \\
\hline Noun & 0 & & Noun & 7 & $3 \%$ \\
\hline Preposition & 0 & & Preposition & 1 & $0.4 \%$ \\
\hline Total & 99 & & Total & 269 & \\
\hline
\end{tabular}

${ }^{a}$ Due to rounding, percentages may add up to more than $100 \%$.

TABLE 11. Distribution of (ing) tokens per progressives vs. other and grammatical constraints not in data: School grade by ethnicity by gender

\begin{tabular}{lccl}
\hline \hline & Progressive & Other & Grammatical Constraint Not in Data \\
\hline Fifth grade & & & \\
African American boys & $69 \%$ & $31 \%$ & Noun/preposition \\
African American girls & $63 \%$ & $37 \%$ & Preposition \\
European American boys & $47 \%$ & $53 \%$ & \\
European American girls & $57 \%$ & $43 \%$ & \\
Second grade & & & \\
African American boys & $61 \%$ & $39 \%$ & Noun/preposition \\
African American girls & $73 \%$ & $27 \%$ & Preposition \\
European American boys & $62 \%$ & $38 \%$ & Noun/preposition/or something \\
European American girls & $63 \%$ & $37 \%$ & Preposition \\
\hline \hline
\end{tabular}

tokens in the progressive category. However, the progressives still provided the largest number of tokens overall for this group as well with the remaining $53 \%$ of the tokens spread across the other seven grammatical constraints. As a consequence of this type of token distribution, as I test the hypothesis I will analyze the data in two general stages. First, I test the hypothesis with all 
TABLE 12. Fifth and second grades by boys and girls for (ing): All grammatical constraints included

Point differences (for [ $\mathrm{n}]$ variant): fifth grade: 11 ; second grade: 8

Chi-square for girls vs. boys: fifth grade: 7.972 , significant at .005; second grade: 2.818 , not significant

\begin{tabular}{|c|c|c|c|c|c|c|c|}
\hline & & \multicolumn{3}{|c|}{ Fifth Grade } & \multicolumn{3}{|c|}{ Second Grade } \\
\hline & & {$[\mathrm{y}]$} & {$[\mathrm{n}]$} & Total & {$[\mathrm{n}]$} & {$[\mathrm{n}]$} & Total \\
\hline \multirow[t]{2}{*}{ Girls } & $n$ & 293 & 121 & 414 & 147 & 89 & 236 \\
\hline & $\%$ & 71 & 29 & & 62 & 38 & \\
\hline \multirow[t]{2}{*}{ Boys } & $n$ & 125 & 85 & 210 & 85 & 73 & 158 \\
\hline & $\%$ & 60 & 40 & & 54 & 46 & \\
\hline \multirow[t]{2}{*}{ Total } & $n$ & 418 & 206 & 624 & 232 & 162 & 394 \\
\hline & $\%$ & 67 & 33 & & 59 & 41 & \\
\hline
\end{tabular}

TABLE 13. Fifth and second grades by boys and girls for (ing): Nouns, prepositions, and "or something" removed

Point differences (for [y] variant): fifth grade: 13; second grade: 8

Chi-square for girls vs. boys: fifth grade: 9.420 , significant at .005; second grade: 1.816 , not significant

\begin{tabular}{|c|c|c|c|c|c|c|c|}
\hline & & \multicolumn{3}{|c|}{ Fifth Grade } & \multicolumn{3}{|c|}{ Second Grade } \\
\hline & & {$[\mathrm{y}]$} & {$[\mathrm{n}]$} & Total & {$[\mathrm{y}]$} & {$[\mathrm{n}]$} & Total \\
\hline \multirow[t]{2}{*}{ Girls } & $n$ & 254 & 108 & 362 & 132 & 84 & 216 \\
\hline & $\%$ & 70 & 30 & & 62 & 38 & \\
\hline \multirow[t]{2}{*}{ Boys } & $n$ & 103 & 78 & 181 & 85 & 72 & 157 \\
\hline & $\%$ & 57 & 43 & & 54 & 46 & \\
\hline \multirow{2}{*}{ Total } & $n$ & 357 & 186 & 543 & 217 & 156 & 373 \\
\hline & $\%$ & 66 & 34 & & 58 & 42 & \\
\hline
\end{tabular}

grammatical constraints included. Second, I test the hypothesis with the constraints of prepositions, nouns, and "or something" removed so that only those grammatical constraints found in all groups are represented.

I use the velar variant as the basis for establishing the degree of difference. See Tables 12 and 13 for initial data and for summaries of the point difference patterns with the two ethnic groups combined. In both tables, the degree of difference between the girls and boys increases, though the degree of increase is small. For instance, in Table 12, with all grammatical constraints included, as we go from the second grade to the fifth, the point differences increase from 8 to 11 . In Table 13, the point differences increase from 8 to 13. Nonetheless, in both cases, there is an increase in the predicted direction. Also, in both cases, there are no significant differences among the girls and boys in second grade, but there are in fifth grade. Moreover, in each analysis of the second grade, the girls show a relatively higher rate of the velar variant and the boys, conversely, a higher rate 
TABLE 14. Fifth and second grades by boys and girls by ethnicity for (ing): All grammatical constraints included

Point differences (for [ $\mathrm{\eta}]$ variant): fifth grade: African Americans: 34, European Americans: 11; second grade: African Americans: 14, European Americans: 9

Chi-square for girls vs. boys: fifth grade: African Americans: 20.980 - significant at .001, European Americans: 6.038 — significant at .025; second grade: African Americans: 2.021— not significant, European Americans: 2.527—not significant

\begin{tabular}{|c|c|c|c|c|c|c|c|}
\hline & & \multicolumn{3}{|c|}{ African American } & \multicolumn{3}{|c|}{ European American } \\
\hline & & {$[\mathrm{y}]$} & {$[\mathrm{n}]$} & Total & {$[\mathrm{y}]$} & {$[\mathrm{n}]$} & Total \\
\hline \multicolumn{8}{|c|}{ Fifth grade } \\
\hline \multirow[t]{2}{*}{ Girls } & $n$ & 106 & 87 & 193 & 187 & 34 & 221 \\
\hline & $\%$ & 55 & 45 & & 85 & 15 & \\
\hline \multirow[t]{2}{*}{ Boys } & $n$ & 12 & 46 & 58 & 113 & 39 & 152 \\
\hline & $\%$ & 21 & 79 & & 74 & 26 & \\
\hline \multicolumn{8}{|c|}{ Second grade } \\
\hline \multirow[t]{2}{*}{ Girls } & $n$ & 32 & 43 & 75 & 115 & 46 & 161 \\
\hline & $\%$ & 43 & 57 & & 71 & 29 & \\
\hline \multirow[t]{2}{*}{ Boys } & $n$ & 12 & 29 & 41 & 73 & 44 & 117 \\
\hline & $\%$ & 29 & 71 & & 62 & 38 & \\
\hline
\end{tabular}

TABLE 15. Fifth and second grades by boys and girls by ethnicity for (ing): Nouns, prepositions, and "or something" removed

Point differences (for [y] variant): fifth grade: African Americans: 34, European Americans: 12; second grade: African Americans: 13, European Americans: 9

Chi-square for girls vs. boys: fifth grade: African Americans: 18.478 - significant at .001, European Americans: 6.418 — significant at .025; second grade: African Americans: 1.493 —not significant, European Americans: 2.081—not significant

\begin{tabular}{|c|c|c|c|c|c|c|c|}
\hline & & \multicolumn{3}{|c|}{ African American } & \multicolumn{3}{|c|}{ European American } \\
\hline & & {$[\mathrm{n}]$} & {$[\mathrm{n}]$} & Total & {$[\mathrm{y}]$} & {$[\mathrm{n}]$} & Total \\
\hline \multicolumn{8}{|c|}{ Fifth grade } \\
\hline \multirow[t]{2}{*}{ Girls } & $n$ & 90 & 77 & 167 & 164 & 31 & 195 \\
\hline & $\%$ & 54 & 46 & & 84 & 16 & \\
\hline \multirow[t]{2}{*}{ Boys } & $n$ & 11 & 43 & 54 & 92 & 35 & 127 \\
\hline & $\%$ & 20 & 80 & & 72 & 28 & \\
\hline \multicolumn{8}{|c|}{ Second grade } \\
\hline \multirow[t]{2}{*}{ Girls } & $n$ & 30 & 42 & 72 & 102 & 42 & 144 \\
\hline & $\%$ & 42 & 58 & & 71 & 29 & \\
\hline \multirow[t]{2}{*}{ Boys } & $n$ & 12 & 28 & 40 & 73 & 44 & 117 \\
\hline & $\%$ & 29 & 71 & & 62 & 38 & \\
\hline
\end{tabular}

of the alveolar variant. Thus, as with (dh), a trend in second grade becomes a significant difference in fifth. Therefore, the prediction is supported so far.

Turning to Tables 14 and 15, I separate the children into the two ethnic groups, first with all grammatical constraints included, and then with the prepositions, 
nouns, and "or something" constraints removed. In each case, similar patterns of divergence occur in that the direction of divergence in both groups goes from less to more with increasing age. Girls and boys are not significantly different in second grade. They become so in fifth. Therefore, the prediction is supported in both ethnic groups. However, unlike the findings for (dh) where the point spreads were similar for the two ethnic groups, here the point spreads and level of significant difference are clearly greater among the African American children.

\section{DISCUSSION AND CONCLUSIONS}

At the outset, I stated the central prediction in these terms. If the degree of separation, and thereby distance, between girls and boys increases during preadolescence, the rates of variants of sociolinguistic variables expressed by girls and by boys may also diverge as the children mature from the early to the later grades of elementary school. The results from this study of young speakers from one public elementary school support this prediction. Girls and boys increasingly diverged from second to fifth grade. Moreover, the patterning of divergent linguistic behavior is similar across ethnicities. The exact numbers differ, and the degrees of divergence differ somewhat, in particular for (ing), but the overall patterns of less to more are similar.

The shared patterning of divergence may be given a coherent and economical account using the framework of the hypothesis that gave rise to the prediction. This involves the multiple findings of increasing gender segregation in childhood plus Bloomfield's principle of density. The increasing degree of linguistic divergence between these girls and boys derives from the increasing gender segregation among them as they grow up within the structures of elementary school. The segregation results in increased distance, or lessened density of interaction, between them, and the increased distance contributes to increased divergence of linguistic usage between the genders.

Additionally, in the process, the children reproduce correlations between gender and linguistic form that are found in the adult community as well. If they reproduce adult patterns, then they are also learning. Therefore, I interpret the stepwise divergence among these children as evidence of the acquisition of gendered linguistic expression in variationist terms. This evidence is visible if and only if we compare and contrast groups of girls and boys. A focus on isolated individuals, in the absence of gender contrasts, will not yield these patterns.

With respect to limitations in the current study, one may immediately point to the small number of African American children represented in the sample of speakers. This limitation should be noted when drawing conclusions beyond this project. However, the patterns that we find with the combined groups of children also play out in the smaller sample of African American children. One may also wish that I had interviewed children from more grades within the school. What kind of divergence patterns could we find if we were able to compare girls and boys in all grades of an elementary school? Future researchers may pursue this. 
Despite these limitations, the data provide a basis for new research questions and opportunities. I will identify two: one new and one old. I begin with a diversity of what I will call polarizations following on the work of Martin and Fabes (2001). If we reinspect Tables 7 and 14, a variety of embedded patterns emerge. In Table 7, between both groups of girls, as one moves from second to fifth grades, there is a slight increase in the rate of the standard variant. For the African American girls, the rates for [ð] are 52\% and 57\%, respectively. The European American girls go from $76 \%$ to $85 \%$. The boys, in contrast, show a stepwise increase in the nonstandard variant. For the African American boys, their pattern for the nonstandard variant of [d] is $58 \%$ in second grade followed by an increase to $73 \%$ in fifth. The European American boys show a similar increase of 30\% to $45 \%$. These represent a mix of significant and nonsignificant differences. The fifth-grade African American boys are significantly different at the .05 level from the second-grade boys with a chi-square value of 4.978. The African American girls in both grades are not significantly different from one another. For the European American boys, we find a clear difference between the fifth and second graders with a chi-square value of 10.124, significant at the .001 level. Likewise, the girls in this group are significantly different across the two grades with a chisquare value of 6.289 at the .05 level.

This type of pattern for the (dh) variable illustrates one of two possible types of increasing gender differences proposed by Martin and Fabes (2001:434), which they call singular polarization and dual polarization. Singular polarization is seen in a "pattern in which the behavior of only one sex changes over time while the behavior of the other sex stays relatively the same." Dual polarization occurs when the groups produce patterns of behavior "in which both boys and girls move away from their starting points but in opposite directions." In both ethnic groups for the (dh) variable, the girls and boys are not significantly different in second grade. If not significantly different, we cannot reject the null hypothesis that they are from the same group. Therefore, their starting points are roughly the same. In turn, the girls show an increase in one variant, the standard fricative, whereas the boys increase their use of the nonstandard stop variant. This suggests a dual polarization. They have begun from a similar starting place and have moved incrementally in opposite directions. This is clearer for the European American children in that significant differences obtain between the girls and boys in fifth grade compared to those in second. The African American girls provide a trend that parallels the European American girls.

Does this pattern repeat in the data for the (ing) variable? Return to Table 14. As with (dh), girls from both ethnic groups show an increase in their rates for the standard variant of [y]. The African American girls go from $43 \%$ in second grade to $55 \%$ in fifth grade, which parallels their behavior for (dh), but this difference does not reach statistical difference. The European American girls go from $71 \%$ to $85 \%$. This difference, with a chi-square value of 8.631 is significant at the .005 level. The boys differ in their patterns yet none result in significant differences across the two grades. Focusing again on the nonstandard variant [n], the African American boys go from $71 \%$ in second grade to $79 \%$ in 
fifth grade, an insignificant increase that roughly parallels their behavior for (dh). However, the European American boys decrease their rate of the nonstandard variant from $38 \%$ to $26 \%$. This is also an insignificant difference but it does not parallel their behavior for (dh). Thus, again the only clear pattern here involves the European American children. The girls are changing. The boys are not. If so, this would be an instance of singular polarization. The African American children provide patterns that hint at dual polarization.

In either case, as with the emergence of gender differences, the different types of polarization may initially appear as insignificant trends. Later, they may acquire a level of statistically significant difference. The childhood gender segregation hypothesis does not, in any clear fashion, provide a basis for explaining these polarizations. The hypothesis predicts divergence, not different types of polarizations. Thus, I have identified one limit of the hypothesis that suggests a few new questions. Why and how do such polarizations emerge when they do? In other words, if divergence can emerge through either a singular or a dual polarization, when, where, and for what type of variable does this happen? Can polarizations differ across social class or other types of sociolinguistic variables? Likewise, might the patterning of polarization differ when comparing a stable variable versus a variable at the mid-range point of a change in progress?

It may be useful here to point out another issue of importance that is not addressed in this research, but which surely is involved in the process of children reproducing adultlike correlations between gender and linguistic form. As we saw, repeatedly, the girls favored, relative to the boys, the standard variants of both stable variables. In turn, the boys favored the variants of both stable variables, which are identified as nonstandard. This is not a new finding (Fischer, 1958; Labov, 1990; Meyerhoff, 2006:207). Because the childhood gender segregation hypothesis predicts increasing divergence, it does not provide, in any clear sense to me, a basis for accounting for these preferences of variant choice. Nonetheless, if this research agenda is to evolve, the issue of preference needs to be explored further for the following reason. In the absence of contrasting preferences, no gender divergence would emerge. The presence of divergence entails differing preferences for setrelated linguistic forms such as the variants of a sociolinguistic variable.

I will suggest that research into why girls favor the standard and boys the nonstandard variants may find different answers for different age groups for a few reasons. One reason may simply involve their early exposure to gendered input at home as reported by Foulkes et al. (2005) and Ely et al. (1996), if it is the case that home provides this. If their mothers, in particular, provide early initiative for girls to favor the standard and boys the nonstandard, then one answer to why these children favor the variants that they do is because of their mothers' early input. In addition, as the children grow up, it seems clear that the children's evaluations of one another change as they increasingly move among peers. In other words, boys have different meanings for girls in second grade and for girls in seventh grade. Likewise, girls have different meanings for second-grade and fifth-grade boys. Thus, not only may the meanings of the variants of these variables change for the children, but the children in relationship to one another and the larger community 
also change as they mature and increasingly come into an awareness of and practice of sexuality (Thorne \& Luria, 1986). Consider the evolving "heterosexual market" as discussed by Eckert (1996; 2000:14-15) and Eckert and McConnell-Ginet (2003:25-27) or the observed changes in border work styles with age in Thorne (1993:70-72). Kerswill and Williams (2000:68) made related points about the changing relational identities of children as they change their orientations to their families, their friends, and then to adults during preadolescence and adolescence. Therefore, it seems reasonable to assume that the social meanings of the variants of these variables could change as the children move through different stages of childhood. After all, the children are learning not only the productive use of linguistic form but also to associate meanings with them. They do this within the context of their relationships with others. If this occurs within the context of relationships, to the extent that the African American and European American children occupy different social networks as they grow up, they may also arrive at differing meanings for the variables of (dh) and (ing). Consider, again, the greater increase in divergence for (ing) among the African American children versus the European American children. This may be related.

It may also be the case that some social evaluations or meanings given to the variants of sociolinguistic forms emerge after, not before, children begin favoring the variants that we have documented here. In other words, girls may come to statistically favor, relatively, the standard variants and boys the nonstandard variants in their speech prior to developing connections between form and social meaning. Recall the previously cited suggestion of Ladegaard and Bleses (2003:228) that children between the ages of 4 and 6 years may be "unaware of the social connotations" of sociolinguistic variables. Some of these connotations may include cognitive connections between linguistic form and social gender. Chevrot, Beaud, and Varga (2000:297) made a related point where they proposed that "it is probable that stylistic skills precede stylistic awareness of the social meaning of variants and situations." And recall Patterson's (1992) finding that stylistic uses of (ing) emerged in young children before significant gender correlations. By "meaning," I mean social meaning or social evaluation as in Campbell-Kibler (2006), whose work on the social evaluations of (ing) may prove useful for determining the content of variant preference among children of differing ages. Because this is a complicated topic that requires investigation beyond the primary concerns of this article, I will not comment more. See Eckert (2000:222--228), Gordon (1997), Meyerhoff (1996), and Wolfram and Schilling-Estes (2006:241-245) for more discussions.

Finally, this research has focused on comparisons across groups of children, contrasting girls with boys along lines of age and ethnicity. But, as noted in Cameron (2005a:29), where I initially explored this hypothesis across the life span in the Spanish of San Juan, Puerto Rico, because " the hypothesis is macro-sociological in scope ... (it) ... is subject to overgeneralization in the face of micro-sociological diversity." By this I meant that there may be individuals or smaller subgroups who differ in theoretically interesting ways from the predicted patterns. Likewise, there may be microsociologically determined contexts of 
language use where divergences diminish. If so, why? In order to pursue this type of research, I assume that we would need long-term ethnographic methods and, perhaps, a team of multiple researchers.

By way of conclusion, I have narrowly pursued and tested a prediction initially found in an endnote in Cameron (2005a:54). The test was carried out in one elementary school among children from differing ethnic, dialect, and to some extent, class backgrounds in order to address certain gaps in this previous research. The prediction was supported. The bases for the prediction provide a basis for accounting for the findings. Increasing gender segregation in childhood results in increasing social distance between girls and boys. As distance increases, they statistically diverge in their speech in a fashion to be expected from dialect research. As they diverge, they recreate correlations in their speech between gender and linguistic form that characterize the adult community. Thus, in this divergence, we find evidence for the acquisition of gendered linguistic expression. In effect, I have provided a social account for an emerging social pattern of language use in childhood. However, as with all research, questions have emerged for future research.

\section{NOTES}

1. I thank Julie Roberts for drawing my attention to this and for help in articulating it.

2. The term middle childhood occurs frequently in social psychological research into childhood. The time frame appears to be from roughly 6 to 12 years of age. Thus, late middle childhood approximately refers to 10 to 12 years of age. Early adolescence would be roughly 13 to 14 .

3. My focus here is on the use of accommodation in discussions of dialect formation, an issue recently questioned in Baxter, Blythe, Croft, and McKane's (2009) critique and test of Trudgill's theory of dialect formation. Yet, in microsociological terms, accommodation has also been explored as a basis for explaining speakers' calculated selections of set-related forms. Consider Meyerhoff's (1998:221) treatment of face-to-face interaction among speakers of Bislama in Vanuatu in contexts where shared social identity was salient. Where social identities were assumed to be shared and salient, speakers strategically selected inclusive pronouns. Where not, speakers opted for other pronominal options. One of the most important identities was gender.

4. One may ask why not use Varbrul for the analysis. The primary purpose of this project is to test the prediction of divergence among girls and boys. Increasing divergence may be understood as an increasing difference between members of a given group with respect to some particular variable. Increasing difference entails the possibility that, at some point, the members of the group were similar enough to belong to just one group in statistical terms. In effect, this is the null hypothesis approach. We can test the null hypothesis via the chi-square test, which operates on the basis of frequency data. Frequency data may be further represented as rates or percentages, as in the work of Wolf and Jiménez (1979), Foulkes et al. (2005:189), and Kerswill and Williams (2000:104). Thus, percentages may serve to illustrate divergence and, in combination with chi-square tests, be used when testing the prediction.

5. The dip here has the shape of a U-shaped learning curve, a pattern documented elsewhere in language acquisition research (Gass \& Selinker, 2001:103, 214-215).

6. When writing the report for the Oak Park School Board on dialect differences, it became clear that most, though not all, of the African American children were speakers of African American Vernacular English (AAVE) to varying degrees. Craig and Washington (2006) provided insightful work on child AAVE. Among the many documented features of AAVE, I found (1) nonreferential 'it' for nonreferential 'there' also known as existential 'it' and 'there,' (2) the use of the past perfect instead of the simple past in narratives, (3) habitual 'be,' (4) deleted 'be,' (5) leveling of the past tense of 'to be' into 'was' across all persons, (6) 'been' as past tense of 'to be,' (7) variable extension of present tense third-person [-s] onto first-person singular verbs, (8) 'steady' as a marker of intensified continuation, and (9) reduplication of the regular past tense suffix in such verbs as 'look' or 'like.' For instance, Michael, an 8-year-old, whom I interviewed with Eddie, a 7-year-old of European descent, says the following:

Michael: They all had a big one. And that was it. ... I liketid the boat a lot. 
Other pronunciation and lexical features (use of ' $y$ 'all') distinguished the children as well. The young African American boy, adopted into a European American family, did not display these features. However, both his parents and the child himself identified him as African American.

7. One reviewer of this research questioned this use of coloring books and Legos on the assumption that it introduced a framework for producing speech that differed stylistically from the interviews carried out with the fifth graders or other second graders who did not play with the coloring books or Legos. In experimental terms, it provided a treatment not given to all children. I will say two things. First, I introduced the coloring books and Legos primarily as a form of distraction, not as a means of sampling speech. I did this in order to accommodate the second graders when they needed to play and to keep them with me during the entire lunchtime that I was responsible for them. In other words, once they became restless and did not really want to talk more, something that happens to 7year-olds during a long day at school, I could not simply return them to their classrooms. They had to stay with me for their entire lunchtime. So, I opened the coloring books and Legos to keep them occupied. Second, as I noted in the text, with coloring books and Legos out, talk became very fragmented as the children focused on coloring or building with Legos. Indeed, some spent this time humming, yawning, singing, or making all kinds of sound effects from both ends as they built and then crashed Lego projects. Therefore, the data that I obtained from the second graders is overwhelmingly from the interview portions of these sessions just as it was in all other sessions.

8. For detailed discussion of the range of occupations within each of these groupings, see the Standard Occupational Classification System Manual for MOG Level Definitions on the Bureau of Labor Statistics’ Website: http://www.bls.gov/.

\section{REFERENCES}

Abrams, Dominic, Rutland, Adam, Pelletier, Joseph, \& Ferrell Jennifer. (2009). Children's group nous: Understanding and applying peer exclusion within and between groups. Child Development 80:224-243.

Aydt, Hillary, \& Corsaro, William. (2003). Differences in children's construction of gender across cultures. American Behavioral Scientist 46:1306-1325.

Bailey, Guy, Wikle, Tom, Tillery, Jan, \& Sand, Lori. (1993). Some patterns of linguistic diffusion. Language Variation and Change 5:359-390.

Bardovi-Harlig, Kathleen. (2000). Tense and aspect in second language acquisition: Form, meaning and use. Oxford: Blackwell Publishing.

Baxter, Gareth, Blythe, Richard, Croft, William, \& McKane, Alan. (2009). Modeling language change: An evaluation of Trudgill's theory of the emergence of New Zealand English. Language Variation and Change 21:257-296.

Bell, Allan. (1984). Language style as audience design. Language in Society 13:145-204.

Benenson, Joyce, Apostoleris, Nicholas, \& Parnass, Jodi. (1998). The organization of children's samesex relationships. In W. Bukowski \& A. Cillessen (eds.), Sociometry then and now: Building on six decades of measuring children's experiences with the peer group. New Directions for Child Development. No. 80. San Francisco: Jossey-Bass Publishers. 5-23.

Blatchford, Peter, Baines, Ed, \& Pellegrini, Anthony. (2003). The social context of school playground games: Sex and ethnic differences, and changes over time after entry to junior school. British Journal of Developmental Psychology 21:481-505.

Bloomfield, Leonard. (1933). Language. Chicago: The University of Chicago Press.

Boberg, Charles. (2004). Real and apparent time in language change: Late adoption of changes in Montreal English. American Speech 79:250-269.

Boyatzis, Chris, Mallis, Michael, \& Leon, Ileana. (1999). Effects of game type on children's genderbased peer preferences: A naturalistic observational study. Sex Roles 40:93-105.

Boyle, D. Ellen, Marshall, Nancy, \& Robeson, Wendy. (2003). Gender at play: Fourth grade girls and boys on the playground. American Behavioral Scientist 46:1326-1345.

Cameron, Deborah. (2006). 'Is there any ketchup, Vera?' Gender, power, and pragmatics. In On language and sexual politics. London: Routledge. 75-92.

Cameron, Richard. (2005a). Aging and gendering. Language in Society 34:23-61.

(2005b). Words of the Windy City. In W Wolfram \& B. Wards (eds.), American voices: How dialects differ from coast to coast. Malden, MA: Blackwell Publishing. 112-117.

Campbell-Kibler, Kathryn. (2007). Accent, (ing), and the social logic of listener perceptions. American Speech 82:32-64.

(2006). Listener perceptions of sociolinguistic variables: The case of (ING). PhD dissertation, Stanford University. 
Cardoso, Walcir. (2007). The variable development of English word-final stops by Brazilian Portuguese speakers: A stochastic optimality theoretic account. Language Variation and Change 19:219-248.

Cheshire, Jenny. (1982). Variation in an English dialect: A sociolinguistic study. Cambridge: Cambridge University Press.

Chevrot, Jean-Pierre, Beaud, Laurence, \& Varga, Renata. (2000). Developmental data on a French sociolinguistic variable: Post-consonantal word-final /R/. Language Variation and Change 12:295-319.

Craig, Holly, \& Washington, Julie. (2006). Malik goes to school: Examining the language skills of African American students from preschool to 5th grade. Mahwah, NJ: Lawrence Erlbaum Associates.

Criswell, Joan. (1939). A sociometric study of race cleavage in the classroom. Archives of Psychology. No. 235. New York: Columbia University Press.

Crompton, Rosemary. (1993). Class and social stratification: An introduction to current debates. Cambridge: Polity Press.

D’Arcy, Alex. (2005). The development of linguistic constraints: Phonological innovations in St. John's English. Language Variation and Change 17:327-355.

de Guzman, Maria Rosario, Carlo, Gustavo, Ontai, Lenna, Koller, Silvia \& Knight, George. (2004). Gender and age differences in Brazilian children's friendship nominations and peer sociometric ratings. Sex Roles 51:217-225.

Díaz-Campos, Manuel. (2005). The emergence of adult-like command of sociolinguistic variables: A study of consonant weakening in Spanish-speaking children. In D. Eddington (ed.), Selected proceedings of the 6th conference on the acquisition of Spanish and Portuguese as first and second languages. Somerville, MA: Cascadilla Proceedings Project. 56-65.

(2004). La adquisición de patrones de variación sociofonológica en el habla infantil. In V. Sánchez Corrales (ed.), Actas XIII Congreso Internacional de la Asociación de Lingüística y Filología de América Latina. San José: Universidad de Costa Rica. 255-266.

Dubois, Sylvie, \& Horvath, Barbara. (2000). When the music changes, you change too: Gender and language change in Cajun English. Language Variation and Change 11: 287-313.

. (1998). Let's tink about dat: Interdental fricatives in Cajun English. Language Variation and Change 10:246-261.

Eckert, Penelope. (2000). Linguistic variation as social practice. Malden, MA: Blackwell Publishing.

(1997). Age as a sociolinguistic variable. In F. Coulmas (ed.), The Handbook of Sociolinguistics. Oxford: Blackwell Publishers Ltd. 151-167.

(1996). Vowels and nail polish: The emergence of linguistic style in the preadolescent heterosexual marketplace. In N. Warner, J. Ahlers, L. Bilmes, M. Oliver, S. Wertheim, \& M. Chen (eds.), Gender and belief systems. Berkeley: Women and Language Group. 183-190.

(1989). The whole woman: Sex and gender differences in variation. Language Variation and Change 1:245-267.

Eckert, Penelope, \& McConnell-Ginet, Sally. (2003). Language and gender. Cambridge: Cambridge University Press.

(1992). Think practically and look locally: Language and gender as community-based practice. Annual Review of Anthropology 21:461-490.

Edelsky, Carole. (1977). Acquisition of an aspect of communicative competence: Learning what it means to talk like a lady. In S. Ervin-Tripp \& C. Mitchell-Kernan (eds.), Child discourse. New York: Academic Press. 225-243.

Ellis, Shari, Rogoff, Barbara, \& Cromer, Cindy. (1981). Age segregation in children's social interactions. Developmental Psychology 17:399-407.

Ely, Richard, Gleason, Jean Berko, \& McCabe, Allyssa. (1996). "Why didn't you talk to your Mommy, Honey?": Parents' and children's talk about talk. Research on Language and Social Interaction 29:7-25.

Erwin, Philip. (1995). Introduction to the transaction edition. In H. Foot, A. Chapman, \& J. Smith (eds.), Friendship and social relations in children. New Brunswick, NJ: Transaction Publishers. vii-xxxvi.

Fabes, Richard, Martin, Carol, \& Hanish, Laura. (2004). The next 50 years: Considering gender as a context for understanding young children's peer relationships. Merrill-Palmer Quarterly 50:260-273.

Fausto-Sterling, Anne. (2000). Sexing the body: Gender politics and the construction of sexuality. New York: Basic Books.

Fischer, John. (1958). Social influences on the choice of a linguistic variant. Word 14:47-56.

Foulkes, Paul, \& Docherty, Gerard. (2006). The social life of phonetics and phonology. Journal of Phonetics 34:409-438. 
Foulkes, Paul, Docherty, Gerard, \& Watt, Dominic. (2005). Phonological variation in child-directed speech. Language 81:177-206.

Gaskins, Suzanne. (2006). The cultural organization of Yucatec Mayan children's social interactions. In X. Chen, D. French, \& B. Schneider (eds.), Peer relationships in cultural context. Cambridge: Cambridge University Press. 283-309.

Gass, Susan, \& Selinker, Larry. (2001). Second language acquisition: An introductory course. 2nd ed. Mahwah, NJ: Lawrence Erlbaum Associates.

Gilbert, Dennis. (1998). The American class structure: In an age of growing inequality. 5th ed. Belmont, CA: Wadsworth Publishing Company.

Goldthorpe, John, \& Hope, Keith. (1974). The social grading of occupations. Oxford: Clarendon Press.

Goodwin, Marjorie. (2001). Organizing participation in cross-sex jump rope: Situating gender differences within longitudinal studies of activities. Research on Language and Social Interaction 34(1): 75-106.

Goodwin, Marjorie, \& Kyratzis, Amy. (2007). Children socializing children: Practices for negotiating the social order among peers. Research on Language and Social Interaction 40: 279-289.

Gordon, Elizabeth. (1997). Sex, speech, and stereotypes: Why women use prestige speech forms more than men. Language in Society 26:47-63.

Gordon, Matthew. (2001). Small town values and big-city vowels: A study of the Northern cities chain shift in Michigan. Durham, NC: American Dialect Society, Duke University Press.

Grinstead, John. (2004). Subjects and interface delay in child Spanish and Catalan. Language 80:40-72.

Guy, Gregory, \& Boyd, Sally. (1990). The development of a morphological class. Language Variation and Change 2:1-18.

Harkness, Sara, \& Super, Charles. (1985). The cultural context of gender segregation in children's peer groups. Child Development 56: 219-224.

Hartrup, Willard. (1983). Peer relations. In P. Mussen \& E. M. Heatherington (eds.), Handbook of child psychology, Volume 4: Socialization, personality, and social development. New York: Wiley. 103-196.

Hazen, Kirk. (2008). (ing): A vernacular baseline for English in Appalachia. American Speech 83:116-140.

Hazen, Kirk. (2006). IN/ING variable. In K. Brown (ed.), The encyclopedia of language and linguistics. 2nd ed. Vol. 5. Oxford: Elsevier. 581-584.

Hempel, Carl. (1966). Philosophy of natural science. Englewood Cliffs, NJ: Prentice-Hall.

Herndobler, Robin. (1993). Sound change and gender in a working class community. In T. Frazer (ed.), "Heartland" English: Variation and transition in the American Midwest. Tuscaloosa: University of Alabama Press. 137-156.

Hinskens, Frans, Kallen, Jeffrey, \& Taeldeman, Johan. (2000). Merging and drifting apart: Convergence and divergence of dialects across political boundaries. International Journal of the Sociology of Language 145:1-28.

Houston, Ann. (1991). A grammatical continuum for (ING). In P. Trudgill \& J. Chambers (eds.), Dialects of English: Studies in grammatical variation. London: Longman. 241-257.

(1985). Continuity and change in English morphology: The variable (ing). $\mathrm{PhD}$ dissertation, University of Pennsylvania.

Huddleston, Rodney. (2002). The verb. In R. Huddleston \& G. K. Pullum (eds.), The Cambridge grammar of the English language. Cambridge: Cambridge University Press. 74-212.

Johnson, Keith. (2006). Resonance in an exemplar-based lexicon: The emergence of social identity and phonology. Journal of Phonetics 34:485-499.

Keller, Rudi. (1994). On language change: The invisible hand in language. London: Routledge.

Kerswill, Paul. (1996). Children, adolescents, and language change. Language Variation and Change $8: 177-202$.

Kerswill, Paul, \& Williams, Ann. (2000). Creating a New Town koine: Children and language change in Milton Keynes. Language in Society 29:65-115.

Kovac, Ceil, \& Adamson, H. D. (1981). Variation theory and first language acquisition. In D. Sankoff \& H. Cedergren (eds.), Variation omnibus. Edmonton: Linguistic Research, Inc. 403-410.

Kyratzis, Amy. (2004). Talk and interaction among children and the co-construction of peer groups and peer culture. Annual Review of Anthropology 33:625-649.

Labov, William. (2001). Principles of linguistic change: Volume 2: Social factors. Malden, MA: Blackwell Publishing. (1994). Principles of linguistic change: Volume 1: Internal factors. Malden, MA: Blackwell Publishing.

(1990). The intersection of sex and social class in the course of linguistic change. Language Variation and Change 2:205-254. 
(1989). The child as linguistic historian. Language Variation and Change 1:85-97.

(1972). The logic of nonstandard English. In Language in the inner city: Studies in the Black English Vernacular. Philadelphia: University of Pennsylvania Press. 201-240.

(1966). The social stratification of English in New York City. Washington, DC: Center for Applied Linguistics.

Labov, William, Ash, Sharon, \& Boberg, Charles. (2006). The atlas of North American English: Phonetics, phonology, and sound change. Berlin: Mouton de Gruyter.

Ladegaard, Hans, \& Bleses, Dorthe. (2003). Gender differences in young children's speech: The acquisition of sociolinguistic competence. International Journal of Applied Linguistics 13:222-233.

LaFreniere, Peter, Strayer, F. F., \& Gauthier, Roger. (1984). The emergence of same-sex preferences among preschool peers. Child Development 55:1958-1965.

Lareau, Annette. (2003). Unequal childhoods: Class, race, and family life. Berkeley: University of California Press.

Larson, Reed, \& Richards, Maryse. (1991). Daily companionship in late childhood and early adolescence: Changing developmental contexts. Child Development 62: 284-300.

Leaper, Campbell. (1994). Exploring the consequences of gender segregation on social relationships. In C. Leaper (ed.), Childhood gender segregation: Causes and consequences. New Directions for Child Development: No. 65. San Francisco: Jossey-Bass Publishers. 67-86.

Levey, Stephen. (2006). The sociolinguistic distribution of discourse marker like in preadolescent speech. Multilingua 25:413-441.

Levine, Robert. (2007). Ethnographic studies of childhood: a historical overview. American Anthropologist 109:247-260.

Lewis, Amanda. (2003). Race in the schoolyard: Negotiating the color line in classrooms and communities. New Brunswick, NJ: Rutgers University Press,

Lockheed, Marlaine. (1986). Reshaping the social order: The case of gender segregation. Sex Roles 14:617-628.

Maccoby, Eleanor. (1998). The two sexes: Growing up apart, coming together. Cambridge, MA: Harvard University Press.

(1988). Gender as a social category. Developmental Psychology 24(6):755-765.

Maltz, Daniel, \& Borker, Ruth. (1982). A cultural approach to male-female miscommunication. In J. Gumperz (ed.), Language and social identity. Cambridge: Cambridge University Press. 196216.

Martin, Carol, \& Fabes, Richard. (2001). The stability and consequences of young children's same-sex interactions. Developmental Psychology 37:431-446.

Martin, Carol, \& Ruble, Diane. (2004). Children's search for gender cues: Cognitive perspectives on gender development. Current Directions in Psychological Science 13:67-70.

McCarthy, Corrine. (2007). Social correlates of vowel shifting in Chicago: A pilot study. McGill Working Papers in Linguistics 21:21-34.

Meyerhoff, Miriam. (2006). Introducing sociolinguistics. London: Routledge.

(1998). Accommodating your data: The use and misuse of accommodation theory in sociolinguistics. Language and Communication 18:205-225.

(1996). Dealing with gender identity as a sociolinguistic variable. In V. Bergvall, J. Bing, \& A. Freed (eds.), Rethinking language and gender research: Theory and practice. London: Longman. 202-227.

Miller, Catherine. (2005). Between accommodation and resistance: Upper Egyptian migrants in Cairo. Linguistics 43:903-956.

Milroy, Lesley. (1987). Language and social networks. 2nd ed. Oxford: Blackwell Publishing.

Moreno, J. L. (1934). Who shall survive? A new approach to the problem of human interrelations. Washington, DC: Nervous and Mental Disease Publishing Co.

Nichols, Patricia. (1983). Linguistic options and choices for Black Women in the rural South. In B. Thorne, C. Kramarae, \& N. Henley (eds.), Language, gender, and society. Rowley, MA: Newbury House Publishers, Inc. 54-68.

Ostermann, Ana Cristina. (2003). Communities of practice at work: Gender, facework and the power of habitus at an all-female police station and a feminist crisis intervention center in Brazil. Discourse and Society 14:473-505.

Overstreet, Maryann. (1999). Whales, candlelight, and stuff like that: General extenders in English discourse. Oxford: Oxford University Press.

Parten, Mildred. (1933-34). Social play among preschool children. Journal of Abnormal and Social Psychology 28:136-147. 
Patterson, Janet Lee. (1992). The development of sociolinguistic phonological variation patterns for (ing) in young children. Ph.D. dissertation, University of New Mexico.

Paugh, Amy. (2005). Multilingual play: Children's code-switching, role-play, and agency in Dominica, West Indies. Language in Society 34:63-86.

Pellegrini, A. D. (2004). Sexual segregation in childhood: A review of evidence for two hypotheses. Animal Behaviour 68:435-443.

Reid, Euan. (1978). Social and stylistic variation in the speech of children: Some evidence from Edinburgh. In P. Trudgill (ed.), Sociolinguistic patterns in British English. Baltimore: University Park Press. 158-171.

Richer, Stephen. (1990). Boys and girls apart: Children's play in Canada and Poland. Ottawa: Carleton University Press.

Roberts, Julie. (2002). Child language variation. In J. K. Chambers, P. Trudgill, \& N. Schilling-Estes (eds.), The handbook of language variation and change. Malden, MA: Blackwell Publishing. 333-348. (1997). Acquisition of variable rules: A study of (-t, d) deletion in preschool children. Journal of Child Language 24:351-372.

(1996). Acquisition of variable rules: (-t,d) deletion and (ing) production in preschool children. Ph.D. dissertation, University of Pennsylvania. IRCS Report No.:96-09. Philadelphia: The Institute for Research in Cognitive Science, University of Pennsylvania.

Roberts, Julie, \& Labov, William. (1995). Learning to talk Philadelphian: Acquisition of short $a$ by preschool children. Language Variation and Change 7:101-112.

Romaine, Suzanne. (1984). The language of children and adolescents: The acquisition of communicative competence. Oxford: Blackwell Publishing.

Sankoff, Gillian, \& Blondeau, Hélène. (2007). Language change across the lifespan: /r/ in Montreal French. Language 83:560-588.

Serbin, Lisa, Moller, Lora, Gulko, Judith, Powlishta, Kimberly, \& Colburne, Karen. (1994). The emergence of gender segregation in toddler playgroups. In C. Leaper (ed.), Childhood gender segregation: Causes and consequences. New Directions for Child Development: No. 65. San Francisco: Jossey-Bass Publishers. 7-17.

Shrum, Wesley, Cheek, Neil, \& Hunter, Sandra. (1988). Friendship in school: Gender and racial homophily. Sociology of Education 61:227-239.

Silva-Corvalán, Carmen, \& Sánchez-Walker, Noelia. (2007). Subjects in early dual language development: A case study of a Spanish-English bilingual child. In K. Potowski \& R. Cameron (eds.), Spanish in contact: Policy, social, and linguistic inquiries. Amsterdam: John Benjamins. 3-22.

Smith, Jennifer, Durham, Mercedes, \& Fortune, Liane. (2007). "Mam, my trousers is fa'in doon!": Community, caregiver, and child in the acquisition of variation in a Scottish dialect. Language Variation and Change 19:63-99.

Strand, Elizabeth. (1999). Uncovering the role of gender stereotypes in speech perception. Journal of Language and Social Psychology 18:86-99.

Strough, JoNell, \& Covatto, Ann Marie. (2002). Context and age differences in same- and other-gender peer preferences. Social Development 11:346-361.

Tannen, Deborah. (1994). Gender and discourse. Oxford: Oxford University Press.

Thorne, Barrie. (1993). Gender play: Girls and boys in school. New Brunswick, NJ: Rutgers University Press.

Thorne, Barrie, \& Luria, Zella. (1986). Sexuality and gender in children's daily worlds. Social Problems $33: 176-190$.

Trudgill, Peter. (2008). Colonial dialect contact in the history of European languages: On the irrelevance of identity to new-dialect formation. Language in Society 37:241-280. Press.

(1974). The social differentiation of English in Norwich. Cambridge: Cambridge University

Tuten, Donald. (2003). Koineization in medieval Spanish. Berlin: Mouton de Gruyter.

Uchida, Aki. (1992). When "difference" is "dominance": A critique of the "anti-power-based" cultural approach to sex differences. Language in Society 21:547-568.

Wald, Benji, \& Shopen, Timothy. (1981). A researcher's guide to the sociolinguistic variable (ING). In T. Shopen \& J. Williams (eds.), Style and variables in English. Cambridge, MA: Winthrop Publishers, Inc. 219-249.

Weinreich, Uriel. (1953). Languages in contact: Findings and problems. The Hague: Mouton.

Whiting, Beatrice, \& Edwards, Carolyn. (1988). Children of different worlds: The formation of social behavior. Cambridge, MA: Harvard University Press. 
Willett, Jerri. (1995). Becoming first graders in an L2: An ethnographic study of L2 socialization. TESOL Quarterly 29:473-503.

Wolf, Clara, \& Jiménez, Elena. (1979). El ensordecimiento del yeísmo porteño: Un cambio fonológico en marcha. In A. M. Barrenechea, M. de Rosetti, M. L. Freyre, E. Jiménez, T. Orecchia, \& C. Wolf (eds.), Estudios lingüísticos y dialectológicos: Temas hispánicos. Buenos Aires: Librería Hachette. $115-135$.

Wolfram, Walt, \& Schilling-Estes, Natalie. (2006). American English. 2nd ed. Malden, MA: Blackwell Publishing. . (1995). Moribund dialects and the endangerment canon: The case of the Ocracoke Brogue. Language 71:696-721.

Youssef, Valerie. (1991). Variation as a feature of language acquisition in the Trinidad context. Language Variation and Change 3:75-101. 